\title{
Inhibition of steel corrosion with imidazolium-based compounds - experimental and theoretical study
}

\author{
Dominik Leguta) \\ IT4Innovations, VŠB-Technical University of Ostrava, 17. listopadu 2172/15, 70800 Ostrava-Poruba, \\ Czech Republic \\ Andrzej Piotr Kądzielawa \\ IT4Innovations, VŠB-Technical University of Ostrava, 17. listopadu 2172/15, 70800 Ostrava-Poruba, \\ Czech Republic and \\ Instyut Fizyki Teoretycznej, Uniwersytet Jagielloński, ulica Eojasiewicza 11, 30-348 Kraków, \\ Poland \\ Petr Pánek \\ Faculty of Materials Science and Technology, Vঙ̌B-Technical University of Ostrava, 17. listopadu 2172/15, \\ 70800 Ostrava, Czech Republic and \\ Institute of Environmental Technology, Vঙ̆B-Technical University of Ostrava, 17. listopadu 2172/15, 708 00 Ostrava, \\ Czech Republic \\ Kristýna Marková, Petra Váňová, Kateřina Konečná, and Šárka Langová \\ Faculty of Materials Science and Technology, Vঙ̆B-Technical University of Ostrava, 17. listopadu 2172/15, \\ 70800 Ostrava, Czech Republic
}

(Dated: 2 August 2021)

This work aims to investigate the corrosion inhibition of the mild steel in the $1 \mathrm{M} \mathrm{HCl}$ solution by 1octyl-3-methylimidazolium hydrogen sulphate 1-butyl-3-methylimidazolium hydrogen sulphate, and 1-octyl3-methylimidazolium chloride, using electrochemical, weight loss, and surface analysis methods as well as the full quantum-mechanical treatment. Polarization measurements prove that studied compounds are mixedtype inhibitors with a predominantly anodic reaction. The inhibition efficiency obtained from the polarization curves is about $80-92 \%$ for all of the 1-octyl-3-methylimidazolium salts with a concentration higher than 0.005 $\mathrm{mol} / \mathrm{l}$, while it is much lower for 1-butyl-3-methylimidazolium hydrogen sulphate. The values measured in the weight loss experiments (after seven days) are to some extent higher (reaching up to $98 \%$ efficiency). Furthermore, we have shown that the influence of the alkyl chain length on the inhibition efficiency is much larger than that of the anion type. Furthermore, we obtain a realistic model of a single molecule on iron surface $\mathrm{Fe}(110)$ by applying the Density Functional Theory calculations. We use the state-of-the-art computational approach, including the meta-GGA strongly-constrained and appropriately normed semilocal density functional to model the electronic structure properties of both free and bounded-to-surface molecules of 1-butyl-, 1-hexyl-, and 1-octyl-3-methylimizadolium bromide, chloride, and hydrogen sulphate. From the calculations we extract, the HOMO/LUMO gap, hardness, electronegativity, and charge transfer of electrons from/to molecules-in-question. It supports the experimental findings and explains the influence of the alkyl chain length and the functional group on the inhibition process.

Keywords: Imidazolium-based compounds; corrosion inhibition; polarization curve; electrochemical impedance spectroscopy; steel; density functional theory; electronic structure; ab-initio methods

\section{INTRODUCTION}

Many organic compounds are effective corrosion inhibitors. Recently, their subset, namely ionic liquids, has captivated the scientific community due to their remarkable properties - low vapour pressure, non-flammability, and thermal stability. They promote the formation of a chelate on a metal surface. Electrons are transferred between an organic compound containing nucleophile centres and metal. Atoms like oxygen, sulphur, and nitrogen, and unsaturated functional groups can share their free electron pairs! 1 The inhibition efficiency is higher if the organic compound can also accept the electrons from the surface of the metal. One of the classes of such compounds is imidazolium derivatives that are widely studied as corrosion inhibitors. The inhibition efficiency usually increases with the increasing length of an alkyl chain. 213
On the other hand, too large molecules can cause a steric hindrance and reduce the inhibition efficiency. Molecules with longer alkyl chains are usually more toxic and less decomposable, although these issues can be predicted employing quantum chemical calculations,$\sqrt{4}$ a useful and economical tool to eliminate potentially problematic candidates before starting the experimental verification process.

Imidazolium and imidazolinium-based compounds are reported to exhibit corrosion resistance on aluminium,,$[5] 6$

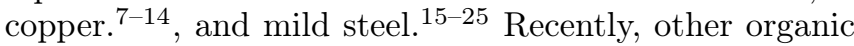
compounds were used as inhibitors on mild steels like Losartan potassium ${ }^{26}$ and Ginkgo leaf extract 27 and tetrazole derivatives for the copper surface. 28

Because of inadequacies of linear voltammetry and electrochemical impedance spectroscopy (EIS), other methods are also applied for the instantaneous determi- 
nation of the corrosion rate. In recent years, the electrochemical frequency modulation technique has caught the attention of corrosion scientists as a rapid and nondestructive method allowing to determine the corrosion rate and polarization resistance without prior knowledge of the Tafel constants. A dual-frequency non-destructive potential wave perturbation around the corrosion potential is applied to corroding metal. This method was also applied to a corrosion study of the carbon steel using imidazolium-based compounds, and the results were compared with those obtained by other electrochemical methods .29

The inhibition mechanism is usually evaluated through the Gibbs energy of adsorption using various adsorption isotherms. The values of $-20 \mathrm{~kJ} \mathrm{~mol}^{-1}$ or less negative indicate electrostatic interaction, and those being $-40 \mathrm{~kJ} \mathrm{~mol}^{-1}$ or more negative indicate the chemisorption process $26|30| 31$

A strong dependence of the inhibition efficiency on the alkyl chain length was found in our previous work ${ }^{32}$ on 1-alkyl-3-methylimidazolium bromides for the shorter chain length, breaking the trend for the largest 1-dodecyl3 -methylimidazolium bromide ${ }^{33}$ this study aims to find out whether the alkyl chain length or the functional group $\left(\mathrm{Br}, \mathrm{Cl}, \mathrm{HSO}_{4}\right)$ has a more significant effect on the inhibition process. The substitution of bromide by hydrogen sulphate could lead to the higher inhibition efficiency via the change of the highest occupied molecular orbital (HOMO) and charge distribution density according to our calculations, as well as previous modelling attempts. 134 These (quantum chemical) calculations are used to predict the interaction between the inhibitor and metal $[34 \sqrt[39]{39}$ The lower the value of the energy difference between HOMO and the lowest unoccupied molecular orbital (LUMO) with respect to the potential energy at infinity, the better the inhibition efficiency. Additionally, the quantities of ionization potential, electron affinity, global hardness, softness, and electronegativity are the key to determining the fraction of electrons transferred from donors (corroded substance) to acceptors (inhibitor), thus quantify the inhibition process.

\section{DETAILS ON CALCULATIONS}

\section{A. Density Functional Theory (DFT)}

We employ the Vienna ab-initio Software Package (VASP) for the computational part, $\stackrel{40,43}{4}$ with the strongly constrained and appropriately normed semilocal density functional (SCAN $\longdiv { 4 4 4 5 }$ meta-GGA. Reciprocal grids of $7 \times 7 \times 1,7 \times 5 \times 1,6 \times 6 \times 1$, and $5 \times 5 \times 5$ for the iron surfaces $\mathrm{Fe}(100), \mathrm{Fe}(110), \mathrm{Fe}(111)$, and bulk bcc Fe are generated by the VASP-embedded routines (Mohnkorst-Pack), see Sec. IV C 1. For the calculations including the molecules, we utilize the $\Gamma$-point-only version of VASP. The exemplary Fe(110) surface in our calculations is represented by a trilayer of 252 iron atoms (three 24.35 by $20.09 \AA$ layers of $2.71 \AA$ thickness) and 30 $\AA$ of vacuum. The design of each molecule is optimized in the box $24.35 \times 20.09 \times 38.12 \AA$ (for visualisation of HOMO and LUMO see Appendix A 1. To orient resultant structures to their principal axes, the Principal Component Analysis (PCA $\sqrt{46}$ is performed, and subsequently, the properties at consecutive distances from the surface are obtained (see Sec. IV C 3). To obtain the same point of reference for each resultant quantity, we determine the so-called workfunction $(\Phi)$, , i.e. the work required to transfer a trial charge to infinity as the value of the local potential of examined system at infinity (along the 'vacuum' axis). Shifting the energy scale by the value of $\Phi$ is equivalent to assuming that $\left.V_{\text {local }}(\mathbf{r})\right|_{\|\mathbf{r}\| \rightarrow \infty}=0$. In Sec. IV C 3 we elaborate on our calculations as well as provide examples. The multiple linear regression taking into account the structural parameters ${ }^{47}$ with the cluster model focused on the geometry optimization $\frac{48}{4}$ is used here.

\section{EXPERIMENTAL}

\section{A. Materials}

A mild steel wire containing wt. $0.1 \% \mathrm{C}, 1.5 \%$ $\mathrm{Mn}, 0.9 \% \mathrm{Si}, 0.03 \% \mathrm{~S}, 0.04 \% \mathrm{P}$ was used for corrosion measurements. The specimens were ground using various grades of emery papers, which ended with the 2000 grade. They were cleaned with bidistilled water, degreased in acetone, and dried. The preparation and analysis of 1-octyl-3-methylimidazolium bromide as described in Ref ${ }^{31}$ 1-octyl-3-methylimidazolium chloride was also prepared by microwave synthesis. 1-alkyl-3-methylimidazolium hydrogen sulphates were prepared by dissolving the corresponding 1-alkyl-3methylimidazolium bromide in isopropyl alcohol. Predried $\mathrm{KHSO}_{4}$ was added to the solution, and the mixture was stirred at room temperature for $14 \mathrm{~h}$. The precipitated $\mathrm{KBr}$ was removed by filtration, and the isopropyl alcohol was evaporated from the liquid phase under reduced pressure. The purity of the product was verified by determining residual bromides by the Mohr method (the purity was higher than 96\%). The yield of hydrogen sulphates was $80-85 \%$. The solutions were prepared by dilution of imidazolium salts in $1 \mathrm{M} \mathrm{HCl}$.

\section{B. Electrochemical measurements}

All the electrochemical measurements were carried out using Voltalab VM 40, Radiometer Analytical. A threeelectrode configuration was used. A steel wire with 0.4 $\mathrm{cm}^{2}$ surface area functioned as the working electrode. A platinum coil and $\mathrm{Ag} / \mathrm{AgCl}$ in $3 \mathrm{M} \mathrm{KCl}$ were used as the auxiliary and reference electrodes. The experiments were carried out at temperature of $21 \pm 2^{\circ} \mathrm{C}$ without stirring. 
The working electrode was immersed into the tested solution for 45 minutes to attain a quasi-equilibrium state. The real equilibrium can hardly be reached. The potentiodynamic polarization curves were recorded in the range from -150 below to $+150 \mathrm{mV}$ above the open circuit potential (OCP) at a scan rate of $1 \mathrm{mV} \mathrm{s}^{-1}$ in the positive direction. The corrosion current density $i_{c o r}$, corrosion potential $E_{\text {cor }}(\mathrm{mV})$, cathodic and anodic Tafel slopes $b_{c}$ and $b_{a}$ and polarization resistance $R_{p o l}\left(\Omega \mathrm{cm}^{2}\right)$ were determined. The inhibition efficiency $I E_{i_{\text {cor }}}(\%)$ was calculated from the following equation, where $\mathrm{i}^{0}$ and $\mathrm{i}^{\mathrm{i}}$ are the corrosion current densities without and with the inhibitor:

$$
I E_{i_{c o r}}=\frac{i_{c o r}^{0}-i_{c o r}^{i}}{i_{c o r}^{0}} \times 100 .
$$

Similarly, the inhibition efficiency of the polarization resistance with $\left(R_{p o l}\right)$ and without inhibitor $\left(R_{\text {pol }}^{0}\right)$ calculated from the Tafel slopes

$$
R_{\text {pol }} \equiv \frac{b_{a}\left|b_{b}\right|}{\log (10) i_{\mathrm{cor}}\left(b_{a}+\left|b_{b}\right|\right)} .
$$

is determined simply by

$$
I E_{R_{p o l}}=\frac{R_{p o l}-R_{p o l}^{0}}{R_{p o l}} \times 100 .
$$

The EIS measurements were carried out in a frequency range from $100 \mathrm{kHz}$ to $100 \mathrm{mHz}$. A sine wave with 5 $\mathrm{mV}$ was used to perturb the system. An equivalent circuit with solution resistance $R_{s}$ in series with the parallel combination of the constant phase element (CPE) and polarization resistance $R_{p}$ was used. The polarization resistance includes all the metal/solution interface resistances - the charge transfer resistance, accumulation resistance, and diffusion layer resistance 34 . The inhibition efficiency was calculated from

$$
I E_{E I S}=\frac{R_{p}-R_{p}^{0}}{R_{p}} \times 100,
$$

where $R_{p}$ and $R_{p}^{0}$ are the polarization resistances of the solution with and without the inhibitor.

The use of CPE represents the more accurate fit in the case of deviation from an ideal capacitor due to different phenomena like surface roughness, inhibitor adsorption, porous layer formation, etc. The equation gives the impedance $\mathrm{Z}$ of $\mathrm{CPE}$

$$
Z_{C P E}=\left[(\mathfrak{i} \omega)^{n} Y_{0}\right]^{-1}
$$

where $\omega$ is the angular frequency $\left(\mathrm{rad} \mathrm{s}^{-1}\right)$, and $\mathfrak{i}$ is an imaginary unit, the capacitance $Y_{0}$ is taken as the capacity of the so-called double layer capacitor, and $n$ is an empirical exponent encompassing the imperfect nature of a physical system (unity in an ideal case) - including but not limited to the surface hardness.

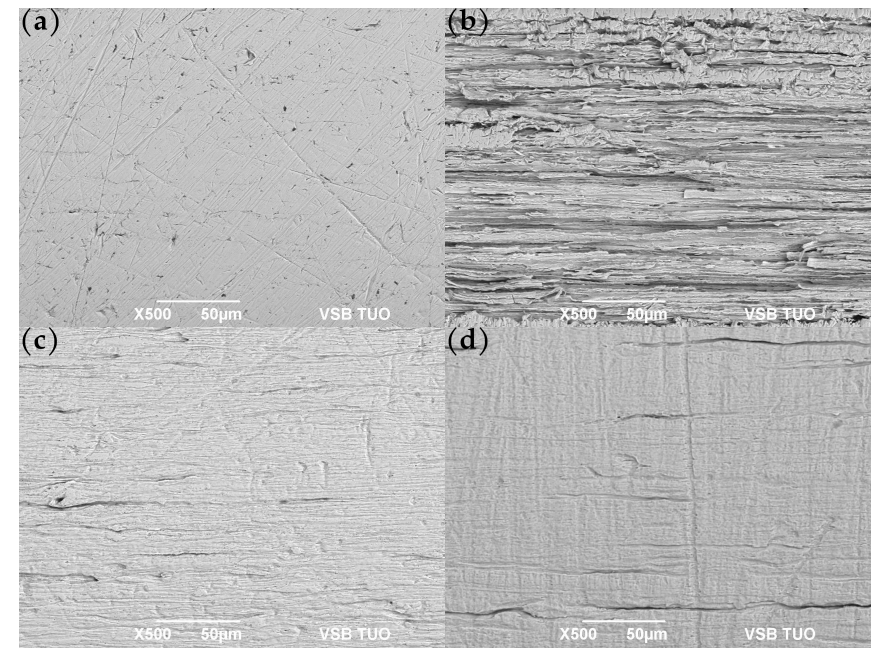

FIG. 1. The surfaces of the wires used in the experiment obtained via the scanning electron microscope (SEM); the cases of the original mild steel wire (a) and wire after 7-day immersion in: $1 \mathrm{M} \mathrm{HCl}$ solution (b), inhibited by $0.001 \mathrm{M} 1$-octyl-3methylimidazolium hydrogen sulphate solution (c), and inhibited by 0.001M 1-octyl-3-methylimidazolium chloride solution (d).

\section{Weight loss measurements and surface analysis}

Gravimetric measurements were carried out with the wires prepared in the same way as the working electrode. The samples weighing about $0.22 \mathrm{~g}$ were immersed into the $1 \mathrm{M} \mathrm{HCl}$ solution with or without the imidazolium salts for seven days, and the weight loss was determined. The inhibition efficiency was calculated from

$$
I E_{W L}=\frac{W L^{0}-W L^{i}}{W L^{0}} \times 100
$$

where $W L^{0}$ is the weight loss in $1 \mathrm{M} \mathrm{HCl}$ solution, and $\mathrm{WL}^{i}$ is the weight loss in the presence of the inhibitor.

The surface analysis was carried out using the scanning QUANTA 450 FEG EDX electron microscope, equipped with the EDX analyser. The snaps were acquired in the secondary electrons mode.

\section{RESULTS AND DISCUSSION}

\section{A. Potentiodynamic polarization curves and electrochemical impedance spectroscopy}

Fig. 2 presents potentiodynamic polarization curves of corrosion inhibition of mild steel in $1 \mathrm{M} \mathrm{HCl}$ in the absence and presence of $0.001 \mathrm{M}$ 1-octyl-3methylimidazolium hydrogen sulphate $\left(\mathrm{C}_{8} \mathrm{MImHSO}_{4}\right)$, 1-octyl-3-methylimidazolium chloride $\left(\mathrm{C}_{8} \mathrm{MImCl}\right)$, 1-octyl-3-methylimidazolium bromide $\left(\mathrm{C}_{8} \mathrm{MImBr}\right)$, 1-butyl-3-methylimidazolium hydrogen sulphate $\left(\mathrm{C}_{4} \mathrm{MImHSO}_{4}\right)$, and 1-dodecyl-3-methylimidazolium 


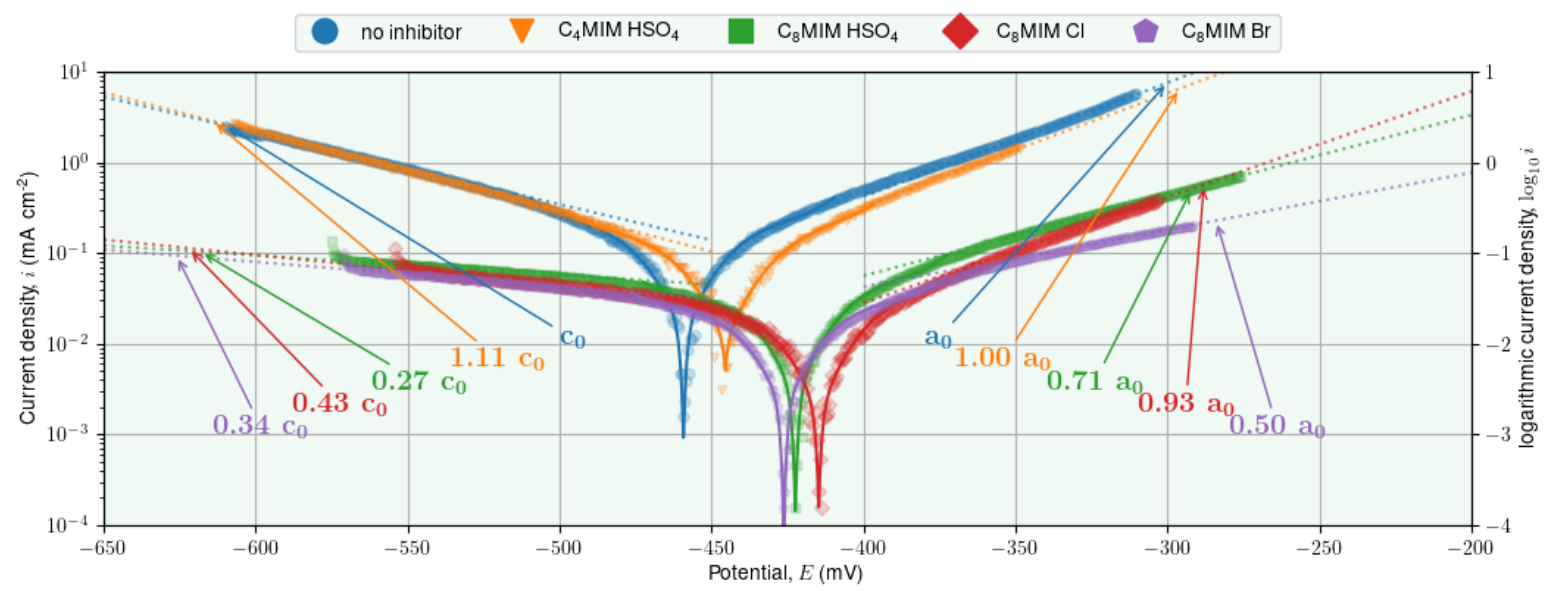

FIG. 2. Potentiodynamic polarization curves of corrosion inhibition of mild steel in $1 \mathrm{M} \mathrm{HCl}$ in the absence and presence of 0.001M 1-octyl-3-methylimidazolium hydrogen sulphate, 1-octyl-3-methylimidazolium chloride, 1-octyl-3-methylimidazolium bromide, and 1-butyl-3-methylimidazolium hydrogen sulphate. The dotted lines represent the linear fit to the tail of the logarithmic current densities $\log i$. The numbers correspond to the ratio of the anodic $(a)$ and cathodic $(c)$ tails with respect to the values for a solution with no inhibitor (blue curve, $a_{0}$ and $c_{0}$ ).

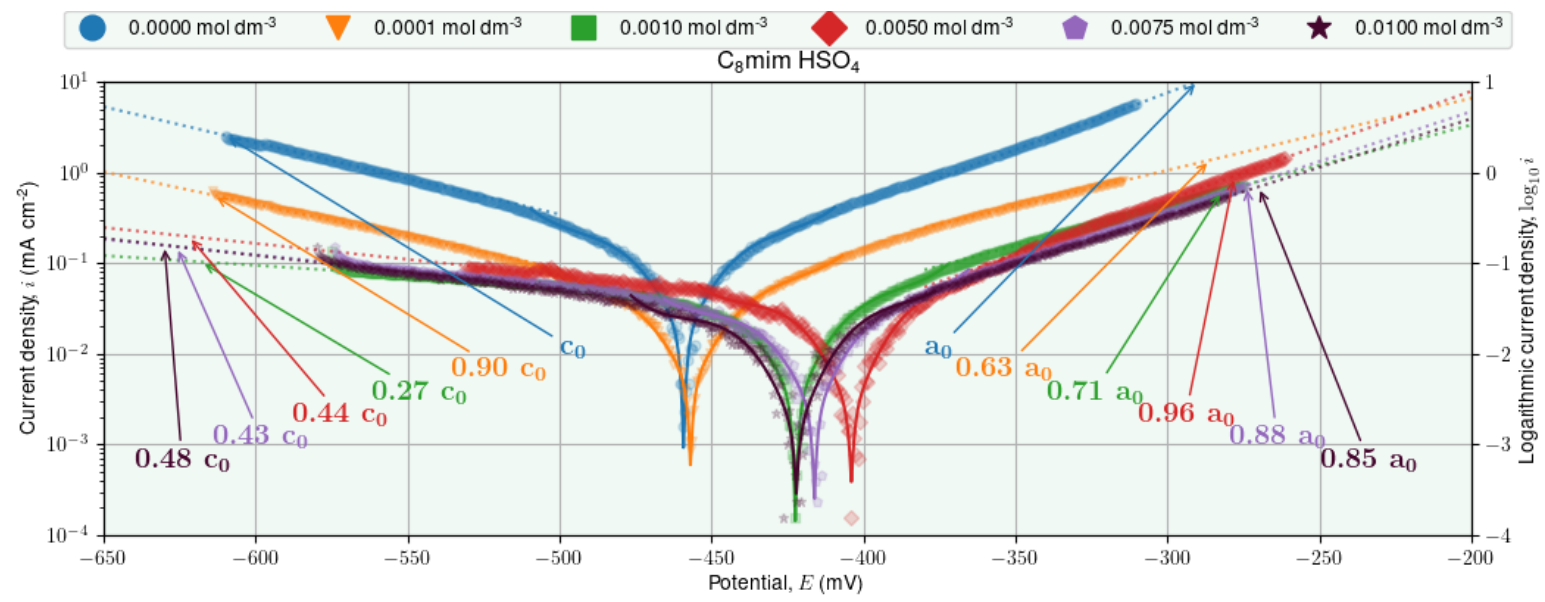

FIG. 3. Potentiodynamic polarization curves of corrosion inhibition of mild steel in $1 \mathrm{M} \mathrm{HCl}$ in the absence and presence of 1-octyl-3-methylimidazolium hydrogen sulphate. The numbers correspond to the ratio of the anodic $(a)$ and cathodic $(c)$ tails with respect to the values for a solution with no inhibitor (blue curve, $a_{0}$ and $c_{0}$ ). Solid lines are a guide to the eye.

bromide $\left(\mathrm{C}_{12} \mathrm{MImBr}\right)$ obtained in the previous study 31 . The cathodic and anodic current densities in the presence of $\mathrm{C}_{8} \mathrm{MImHSO}_{4}, \mathrm{C}_{8} \mathrm{MImCl}$, and $\mathrm{C}_{8} \mathrm{MImBr}$ are much lower than $\mathrm{C}_{4} \mathrm{MImHSO}_{4}$ being just very close to the pure $1 \mathrm{M} \mathrm{HCl}$ solution indicating that $\mathrm{C}_{4} \mathrm{MImHSO}_{4}$ is a rather limited inhibitor. The lowest current densities can be seen for $\mathrm{C}_{8} \mathrm{MImBr}$, but the differences are not significant. It seems that the inhibition efficiencies for all the salts with eight carbons chains are similar. The results are summarized in Tab. IVA and indicate that the length of the alkyl chain plays a more significant role than the type of anion. These findings are also supported by quantum-mechanical modelling; see below. Figs. 3 and 4 show the potentiodynamic polarization curves for various concentrations of $\mathrm{C}_{8} \mathrm{MImHSO}_{4}$ and $\mathrm{C}_{8} \mathrm{MImCl}$. The marked differences of current densities can be seen only between 0.0001 and $0.001 \mathrm{M}$ solutions of both salts. The corrosion potentials are shifted to the positive direction compared with the $\mathrm{HCl}$ solution except for $0.0001 \mathrm{M} \mathrm{C}_{8} \mathrm{MImCl}$. The values of $i_{c o r}$ differ less than $85 \mathrm{mV}$ from the blank; hence both salts exhibit the traits of mixed-type inhibitors with a prevailing anodic effect ${ }^{27|36 / 49| 50}$. The presence of inhibitors causes the anodic and cathodic current density to fall. The electrochemical polarization parameters and the inhibition efficiency calculated from the corrosion current density are reported in Table II. It is seen in Figs. 3 and 4 that the Tafel slopes are not totally parallel for both anodic and cathodic reactions for different inhibitor concentrations, hence a possible modification of the inhibiting mechanism might occur. The inhibition efficiencies are very similar for both salts with the same 


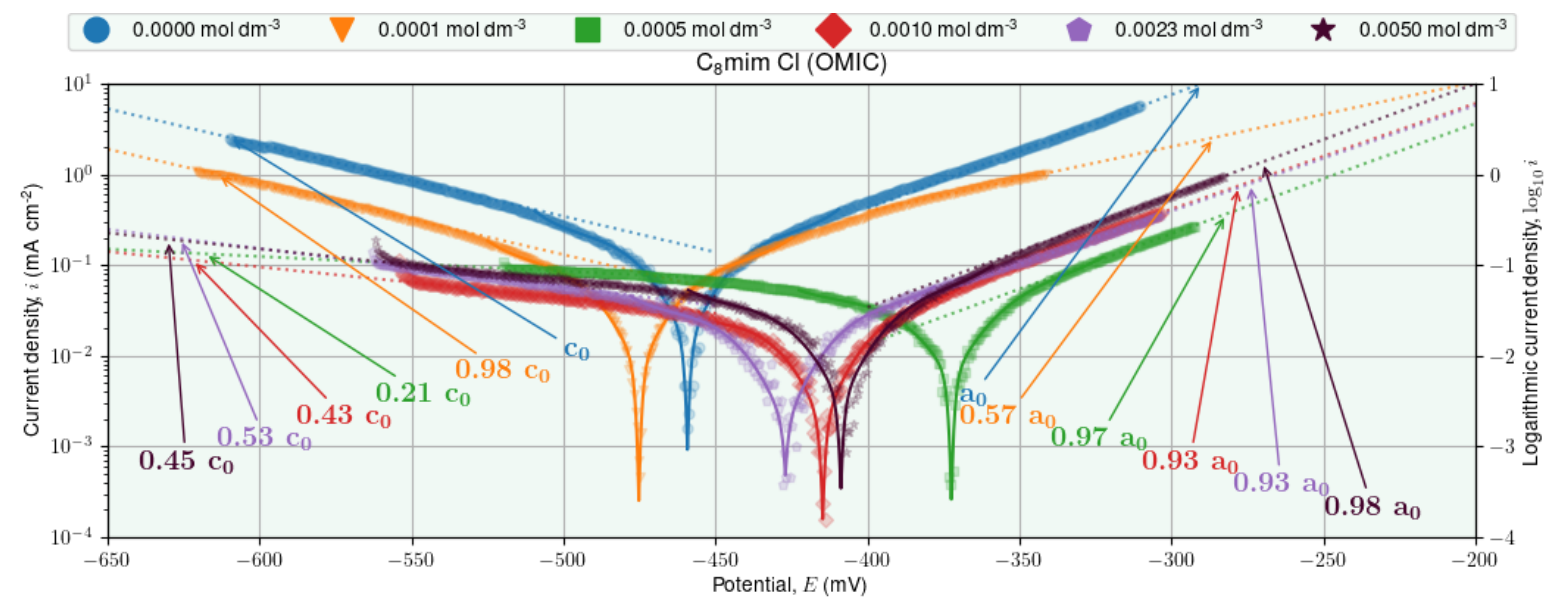

FIG. 4. The same as in Fig 3 but for $\mathrm{C}_{8} \mathrm{MImCl}$. Solid lines are a guide to the eye.

TABLE I. Electrochemical polarization parameters for mild steel in $1 \mathrm{M} \mathrm{HCl}$ solution in the absence and presence of 1-octyl3-methylimidazolium chloride, 1-octyl-3-methylimidazolium hydrogen sulphate and 1-butyl-3-methylimidazolium hydrogen sulphate at $20^{\circ} \mathrm{C}$.

\begin{tabular}{|c|c|c|c|c|c|c|c|c|}
\hline & $c(\mathrm{~mol} / \mathrm{l})$ & $a(m V / d e c)$ & $-b_{c}(m V / d e c)$ & $E_{\text {cor }}(m V)$ & $\mathrm{i}_{\text {cor }}\left(\mathrm{mA} / \mathrm{cm}^{2}\right)$ & $I E_{i_{c o r}}(\%)$ & $R_{p o l}\left(\Omega \mathrm{cm}^{2}\right)$ & $I E_{R_{p o l}}(\%)$ \\
\hline & $\varnothing$ & 80 & 126 & -443 & 122.0 & & 174 & \\
\hline \multirow{5}{*}{$\mathrm{C}_{8} \mathrm{MImHSO}_{4}$} & $0.110^{-3}$ & 126 & 141 & -466 & 50.3 & 59 & 574 & 70 \\
\hline & $1.010^{-3}$ & 113 & 465 & -418 & 38.5 & 68 & 1024 & 83 \\
\hline & $5.010^{-3}$ & 83 & 285 & -399 & 32.4 & 73 & 865 & 80 \\
\hline & $7.510^{-3}$ & 91 & 296 & -403 & 26.8 & 78 & 1125 & 84 \\
\hline & $10.010^{-3}$ & 93 & 263 & -408 & 22.8 & 81 & 1314 & 87 \\
\hline \multirow[t]{4}{*}{$\mathrm{C}_{8} \mathrm{MImCl}$} & $0.110^{-3}$ & 140 & 129 & -484 & 98.1 & 20 & 297 & 41 \\
\hline & $1.010^{-3}$ & 86 & 295 & -410 & 21.6 & 82 & 1336 & 87 \\
\hline & $2.310^{-3}$ & 86 & 238 & -405 & 23.1 & 81 & 1183 & 85 \\
\hline & $5.010^{-3}$ & 81 & 284 & -404 & 30.7 & 75 & 892 & 80 \\
\hline $\mathrm{C}_{4} \mathrm{MImHSO}_{4}$ & $1.010^{-3}$ & 80 & 114 & -444 & 91.8 & 25 & 222 & 22 \\
\hline
\end{tabular}

concentration. The highest concentration was not used for chloride because of the similar values of the corrosion current densities for 0.001 and $0.005 \mathrm{M}$ solutions. The differences between $\mathrm{C}_{8} \mathrm{MImHSO}_{4}$ and $\mathrm{C}_{8} \mathrm{MImCl}$ can be attributed to the various purity or subjectivity of the evaluation rather than to the various properties of the compounds. Only one concentration was applied for $\mathrm{C}_{4} \mathrm{MImHSO}_{4}$ since the inhibition efficiency was low.

The EIS measurements were evaluated using the EIS analyser software. In Figs 5, 6, and 7 on the left, we present Nyquist plots of corrosion inhibition of mild steel in $1 \mathrm{M} \mathrm{HCl}$ in the absence and presence of 1-octyl3-methylimidazolium hydrogen sulphate and 1-octyl-3methylimidazolium chloride. The lines present the fitted spectrum, and the points indicate the experimental values. For each inhibitor, the spectra exhibit one depressed capacitive loop while Bode plots (right side of Figs 5, 6. and 7) reveal a new phase angle shift that indicates there are two-time constants in some cases (e.g., $\mathrm{C}_{8} \mathrm{MIm} \mathrm{HSO}_{4}$ with concentration $0.0001 \mathrm{~mol} / \mathrm{l}$ ). Capacitive loops probably coincide, and the protective layer formation cannot be seen in Nyquist plots. The values obtained from EIS measurement are presented in Table III. The solution re- sistances are not reported in thisTab.because of the considerable calculation error. The values were less than 2 $\Omega \mathrm{cm}^{2}$. Except for the $0.0001 \mathrm{M}$ solutions, the inhibition efficiencies of $\mathrm{C}_{8} \mathrm{MIm} \mathrm{HSO}_{4}$ and $\mathrm{C}_{8} \mathrm{MImCl}$ are almost independent on the inhibitor concentration and reach the values of about $90 \%$. The differences between the voltammetric and EIS measurements can be explained by the unequal time of measurement, and the OCP value can slightly change with time. As to $\mathrm{C}_{4} \mathrm{MImHSO}_{4}$, additional experiments would be necessary, but they were not carried out because of the low inhibition efficiency.

\section{B. Weight loss measurements and surface analysis}

The results of the weight loss measurements are shown in Table III The experiments were not carried out with $\mathrm{C}_{4} \mathrm{MImHSO}_{4}$ because of the low inhibition efficiency found by the electrochemical measurements. The inhibition efficiency slightly increased after seven days of immersion into the solutions. Figure 1 shows the mild steel surface after 7 days immersion into $1 \mathrm{M} \mathrm{HCl}$ solution and into $0.001 \mathrm{M}$ 1-octyl-3-methylimidazolium hydrogen sul- 

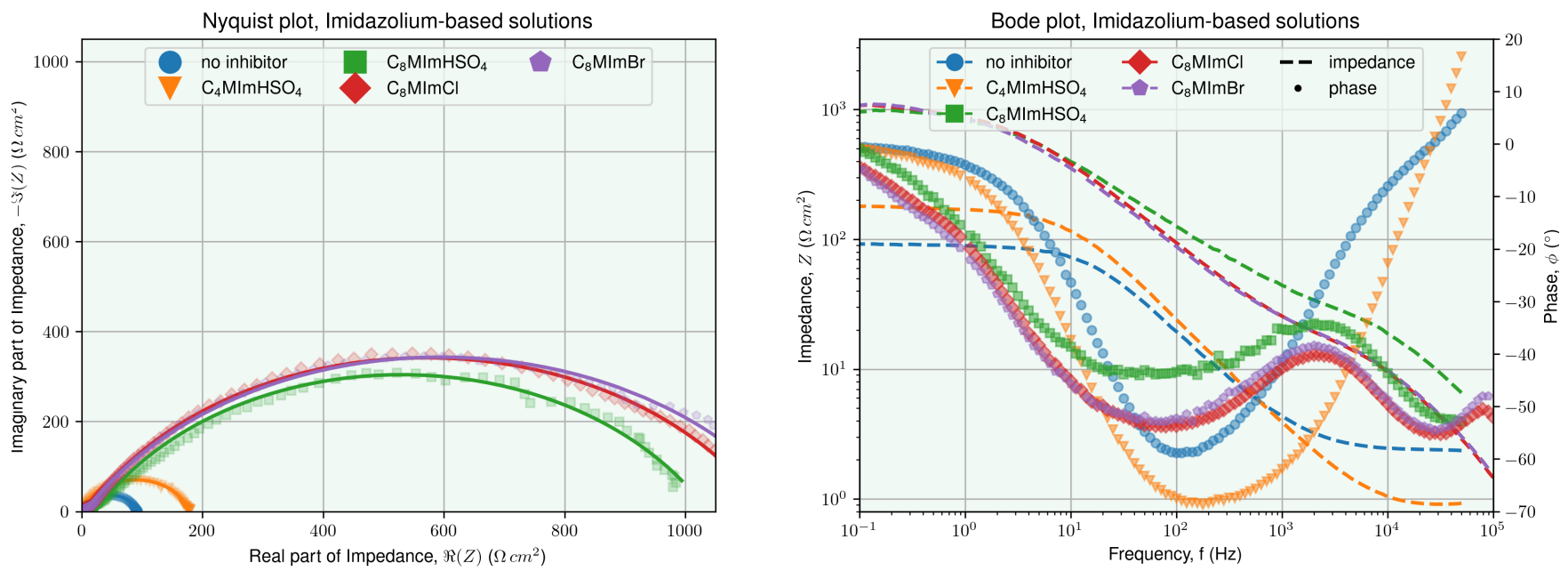

FIG. 5. Nyquist (left) and Bode (right) plots of corrosion inhibition of mild steel in $1 \mathrm{M} \mathrm{HCl}$ in the absence and presence of different imidazolium-based compounds. Note the qualitative changes in the Bode plot: From a simple sharp minimum of the phase for the absence of inhibitor (blue dots) to either broadened valley (for $\mathrm{C}_{8} \mathrm{MImHSO}_{4}$ ) or two distinctive minima (e.g., $\left.\mathrm{C}_{8} \mathrm{MImBr}\right)$. For details, see the main text.
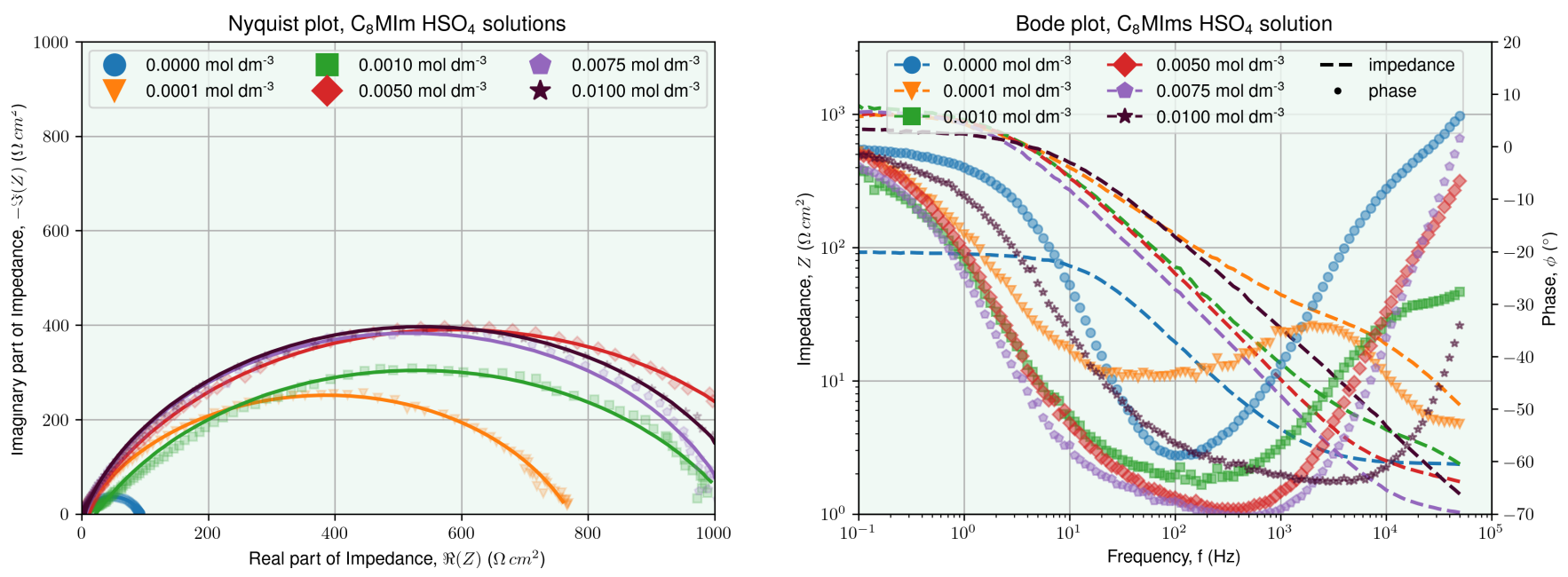

FIG. 6. Nyquist (left) and Bode (right) plots of corrosion inhibition of mild steel in $1 \mathrm{M} \mathrm{HCl}$ in the absence and presence of 1-octyl-3-methylimidazolium hydrogen sulphate. For details, see the main text.

phate and $0.001 \mathrm{M}$ 1-octyl-3-methylimidazolium chloride solution. The surface in the presence of both inhibitors is much less damaged than in $1 \mathrm{M} \mathrm{HCl}$ solution.

\section{Theoretical modelling}

We performed quantum-mechanical calculations to elucidate the inhibition reaction and quantify it by several descriptors, starting from the clean iron surface and adsorbed molecules. For the naming conventions, we refer the reader to Appendix $\mathrm{A}$

\section{1. iron surfaces}

In order to investigate electronic structure properties of various adsorbed molecules we start with modeling of the bcc iron (space group Im-3m, $a=b=c=2.87 \AA$, $\alpha=\beta=\gamma=90^{\circ}$ ), then calculate its electronic properties in: (i) the bulk, (ii) the $\mathrm{Fe}(100)$ surface, (iii) the $\mathrm{Fe}(110)$ surface, and (iv) the $\mathrm{Fe}(111)$ surface.

The most stable iron surface is the one with the lowest surface energy $\gamma \underline{51}$

$$
\gamma=\frac{E_{\mathrm{slab}}-N \cdot E_{\mathrm{bulk}}}{2 A},
$$

where $E_{\text {slab }}$ is the energy of a slab of $N$ atoms with area $A$ exposed to vacuum, and $E_{\text {bulk }}$ is the energy (per 

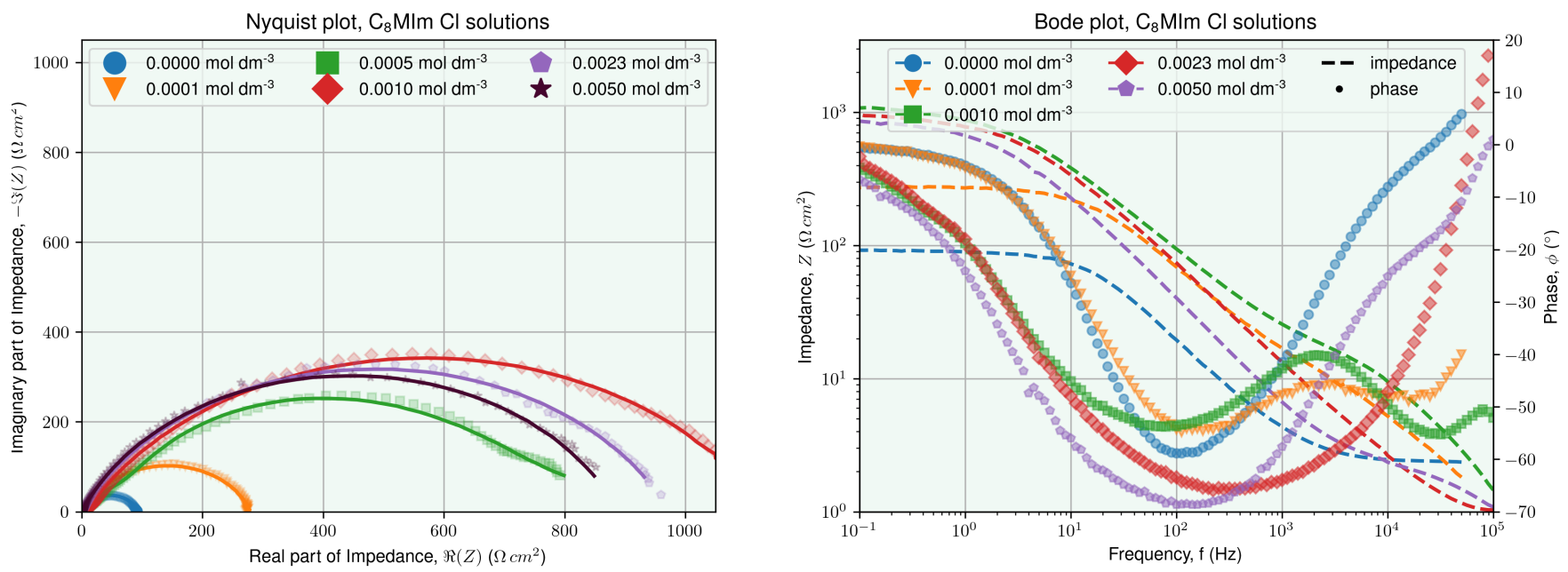

FIG. 7. Nyquist (left) and Bode (right) plots of corrosion inhibition of mild steel in $1 \mathrm{M} \mathrm{HCl}$ in the absence and presence of 1-octyl-3-methylimidazolium chloride. For details, see the main text.

TABLE II. Parameters of the Electrochemical Impedance Spectroscopy (EIS), namely, the polarization resistance $\left(\mathrm{R}_{\mathrm{p}}\right)$, capacity $\left(c_{d l}\right)$, impedance-frequency exponent $\left(\mathrm{n}, c f\right.$. (5)), and the inhibition efficiency (IE $\left.\mathrm{E}_{\mathrm{ES}}\right)$, concatenated for the case of mild steel in $1 \mathrm{M} \mathrm{HCl}$ solution both in the absence and presence of 1-octyl-3-methylimidazolium hydrogen sulphate, 1-octyl-3methylimidazolium chloride, and 1-butyl-3-methylimidazolium hydrogen sulphate at $20^{\circ} \mathrm{C}$.

\begin{tabular}{l|rrrrrl} 
& $\mathrm{c}(\mathrm{mol} / \mathrm{l})$ & $\mathrm{R}_{\mathrm{p}}\left(\Omega \mathrm{cm}^{2}\right)$ & $C_{d l}\left(\mu F \mathrm{~cm}^{-2}\right)$ & $n$ & $\mathrm{IE}_{\mathrm{EIS}}(\%)$ \\
\hline & $\varnothing$ & 89 & 179 & 0.88 & \\
\hline $\mathrm{C}_{8} \mathrm{MImHSO}_{4}$ & 0.1 & $10^{-3}$ & 771 & 69 & 0.74 & 88 \\
& 1.0 & $10^{-3}$ & 1015 & 113 & 0.78 & 91 \\
& 5.0 & $10^{-3}$ & 1173 & 113 & 0.75 & 92 \\
& 7.5 & $10^{-3}$ & 1028 & 89 & 0.82 & 91 \\
& 10.0 & $10^{-3}$ & 1072 & 116 & 0.81 & 92 \\
\hline $\mathrm{C}_{8} \mathrm{MImCl}$ & 0.1 & $10^{-3}$ & 273 & 70 & 0.82 & 67 \\
& 1.0 & $10^{-3}$ & 1130 & 121 & 0.69 & 92 \\
& $2.310^{-3}$ & 974 & 115 & 0.74 & 91 \\
& 5.0 & $10^{-3}$ & 889 & 167 & 0.76 & 90 \\
\hline $\mathrm{C}_{4} \mathrm{MImHSO}_{4}$ & 1.0 & $10^{-3}$ & 176 & 154 & 0.86 & 49
\end{tabular}

TABLE III. The Inhibition efficiency $\left(I E_{W L}\right)$ of $\mathrm{C}_{8} \mathrm{MImHSO}_{4}$ and $\mathrm{C}_{8} \mathrm{MImCl}$ after 7 days, from the weight loss (WL) measurements for different concentrations of respective inhibitors.

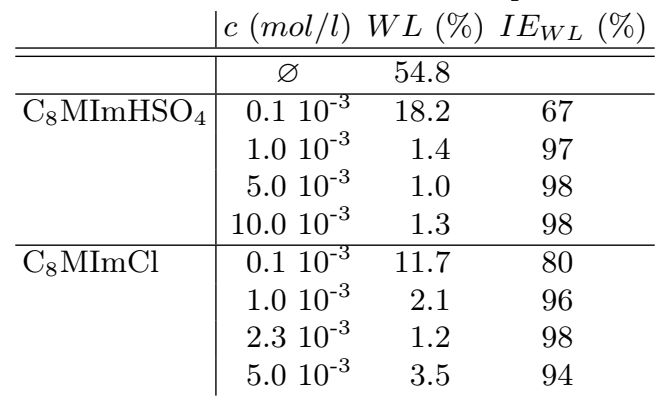

atom) of the bcc iron. As illustrated in Table IV the surface energy is minimized for $\mathrm{Fe}(110)$, which is consistent both with the experimental data $2^{52}$ and the precedent calculations 53 .
TABLE IV. The surface energy $\gamma$ for slabs of $N$ atoms and energy $E_{G}$, with the area $A$ exposed to vacuum.

\begin{tabular}{c|rrrrr}
\multicolumn{1}{c}{$N$} & $\frac{E_{G}}{N}(\mathrm{eV})$ & $A\left(\AA^{2}\right)$ & $\gamma\left(\mathrm{eV} \AA^{-2}\right)$ & $\gamma\left(\mathrm{J} \mathrm{m}^{-2}\right)$ \\
\hline \hline bulk & 54 & -8.34069 & & & \\
$\mathrm{Fe}(100)$ & 108 & -8.12508 & 74.132 & 0.157 & 2.52 \\
$\mathrm{Fe}(111)$ & 108 & -7.92548 & 128.401 & 0.175 & 2.80 \\
$\mathrm{Fe}(110)$ & 72 & -8.04459 & 69.893 & 0.153 & 2.44 \\
\hline \multicolumn{5}{c}{ W.R. Tyson and W.A. Miller ${ }^{52]}$} & 2.41 \\
I. H. Sahputra et al. ${ }^{53}$ & & 2.44
\end{tabular}

\section{Free molecules}

As a starting point of our modelling, we optimize the free molecules and obtain their chemical properties, i.e., the energy of the Highest Occupied Molecular Orbital $\left(\mathrm{E}_{\mathrm{HOMO}}\right)$ and the Lowest Unoccupied Molecular Orbital 
TABLE V. The electronic properties of single molecules $(\bigcirc \mathrm{MI} \square$ ): the HOMO/LUMO energies, hardness $\eta$, electronegativity $\chi$. For definitions, see main text. The greycolored cells correspond to the 'harder' spin-orbital.

\begin{tabular}{l|rr|rr} 
& $E_{\text {HOMO }}$ & $E_{\text {LUMO }}$ & \multicolumn{2}{c}{$\chi$} \\
\hline BMIM $\sigma=\downarrow$ & -5.33 & -0.86 & 2.23 & 3.09 \\
HMIM $\sigma=\downarrow$ & -5.32 & -0.82 & 2.24 & 3.07 \\
OMIM $\sigma=\downarrow$ & -5.31 & -0.83 & 2.24 & 3.07 \\
\hline BMIM $\sigma=\uparrow$ & -2.13 & -0.22 & 0.96 & 1.17 \\
HMIM $\sigma=\uparrow$ & -2.09 & -0.21 & 0.94 & 1.15 \\
OMIM $\sigma=\uparrow$ & -2.10 & -0.22 & 0.94 & 1.15 \\
\hline BMIB & -4.47 & -1.67 & 1.40 & 3.07 \\
HMIB & -4.52 & -1.67 & 1.42 & 3.10 \\
OMIB & -4.56 & -1.67 & 1.44 & 3.11 \\
\hline BMIC & -4.70 & -1.49 & 1.60 & 3.09 \\
HMIC & -4.83 & -1.56 & 1.63 & 3.19 \\
OMIC & -4.81 & -1.55 & 1.64 & 3.19 \\
\hline BMIS & -5.32 & -1.82 & 1.75 & 3.57 \\
HMIS & -5.37 & -1.86 & 1.76 & 3.61 \\
OMIS & -5.39 & -1.82 & 1.79 & 3.62
\end{tabular}

$\left(\mathrm{E}_{\mathrm{LUMO}}\right)$, the hardness

$$
\eta \equiv \frac{1}{2}\left(-E_{\mathrm{HOMO}}+E_{\mathrm{LUMO}}\right),
$$

and electronegativity

$$
\chi \equiv-\frac{1}{2}\left(E_{\mathrm{HOMO}}+E_{\mathrm{LUMO}}\right) .
$$

The quantitative results are summarized in Tab. V] The groups $-\mathrm{Br},-\mathrm{Cl}$, and $-\mathrm{HSO}_{4}$ change the electronegativity by $300-400 \%$ and hardness $\eta$ only by $50-100 \%$ compared to the molecules without any of the aforementioned group. The effect of the length of the alkyl chain $\left(\mathrm{C}_{\mathrm{n}} \mathrm{H}_{2 \mathrm{n}+1}\right)$ is small - both quantities increase slightly ( $5 \%$ ) with the increasing $n$.

A note concerning the electronic nature of the bonding of 1-alkyl-3-methyl-imidazolium with an extra functional group - either Halogens (Bromide \& Chloride) or hydrogen sulphate $\left(\mathrm{HSO}_{4}\right)$ is to be made here. By performing the Bader charge analysis $\stackrel{54}{,}$ we obtain the resultant charge enclosed in the specific volume (by creating the potential-weighed Voronoi diagram) for each atom. The results are presented in Tab. VI. Note that the additional group attracts an electron from 1-butyl3-methyl-imidazolium, indicating an ionic-like bond between the group and BMIM. The transfer of an electron to the functional group warrants the prospective electron transfer from the iron surface to an imidazoliumbased compound. The results for 1-hexyl- and 1-octylare qualitatively the same and, as such, are omitted here.

\section{A molecule on iron (110) surface}

The effect of the HOMO and LUMO energy levels modified by the presence of the molecules close to the $\mathrm{Fe}(110)$
TABLE VI. The effective charge (in units of $|e|$ ) on each atom of 1-butyl-3-methyl-imidazolium without (first column) and with functional group (Bromide, Chloride, and hydrogen sulphate, respectively) obtain by the Bader charge analysis 54 (hence fractional values). The numbering of carbon and nitrogen atoms corresponds to the schematic figure on the left.

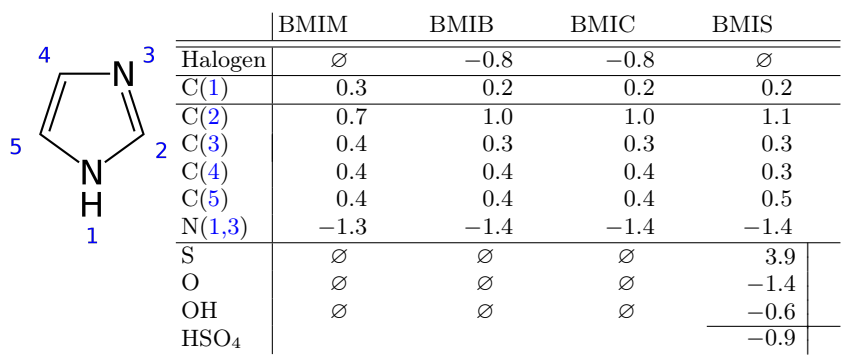

surface are presented here. It allows us to examine the impact of the iron surface on the HOMO-LUMO gap, hardness $\eta$, and electronegativity $\chi$. Furthermore, we obtain the electronic structure for different distances of the $\bigcirc \mathrm{MI} \square$ molecules from the surface (, i.e., the distance between the molecular centre of mass $(\mathrm{CM})$ and the last layer of the $\mathrm{Fe}(110)$ surface) orienting the principal axis of the molecule (via the principal component analysis 46 ).

We define the adsorption energy as 55156

$E_{\text {ads }} \equiv E_{\text {molecule on surface }}-\left(E_{\text {free molecule }}+E_{\text {clean surface }}\right)$.

In Fig. 8 we show the adsorption energy $\left(E_{\text {ads }}\right)$ versus the distance $h$ between the molecule and Fe surface.

In the next subsection (IV C 4), we test the formula for the charge expected transfer

$$
\begin{aligned}
\Delta N=N_{\text {surface }}^{e}-N_{\text {free }}^{e} & \approx \frac{\chi_{\mathrm{Fe}}-\chi_{\bigcirc \mathrm{MI} \square}}{2\left(\eta_{\mathrm{Fe}}+\eta_{\bigcirc \mathrm{MI} \square}\right)} \\
& \approx \frac{-E_{F}-\chi_{\bigcirc \mathrm{MI} \square}}{2 \eta_{\bigcirc \mathrm{MI} \square}},
\end{aligned}
$$

(cf. Dohare, et al.57), both for the energy levels of the free-molecules with pure (non-interacting) Fe surface, as well as for the interacting system of $\bigcirc \mathrm{MI} \square$ on $\mathrm{Fe}(110)$.

\section{Workfunction}

We estimate the so-called workfunction $\Phi$, as a negative value of the local potential of the system in question at infinity along the 'vacuum' axis c (i.e., averaged along $\mathbf{a}$ and $\mathbf{b}$ ). In Fig. 9, we illustrate this process on the exemplary cases of pure $\mathrm{Fe}(110)$ surface and BMIB on $\mathrm{Fe}(110)$. Ultimately, we add the value of $\Phi$ from the energy scale per case, resulting in comparable data.

\section{Electronic properties of molecules on iron surface}

The main aim of the modelling described above is to determine the charge transfer to the adsorbed molecule 

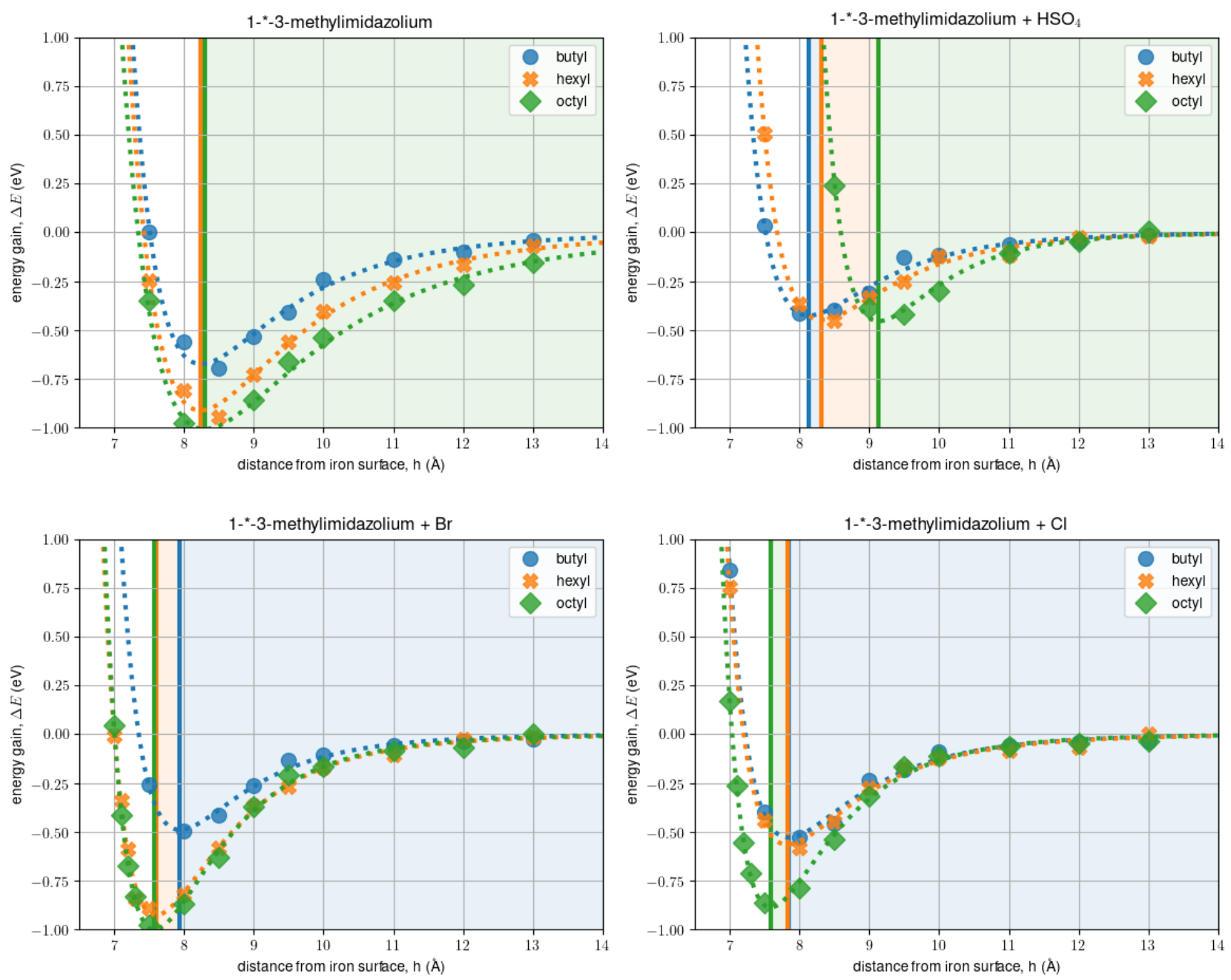

FIG. 8. Relative energy $\Delta E \equiv E-E_{0}$ of molecules:: oMIM (top left), oMIS (top right), oMIB (bottom left), and oMIC (bottom right), versus the distance between their respective center of mass and the $\mathrm{Fe}(110)$ surface $(h)$ along c. The vertical lines mark the equilibrium distance $h_{0}$.

to estimate the corrosion inhibition efficiency. We compare the results (i) obtained via the separate calculations (i.e., assuming that the interaction with surface does not significantly change the chemistry of $\bigcirc \mathrm{MI} \square$ molecules); (ii) extending (11) to the system of $\bigcirc \mathrm{MI} \square$ interacting with $\mathrm{Fe}(110)$ surface; (iii) via the Bader charge analysis 54 of the latter model. In Table VII we calculate the chemical quantities as described in Sec. IVC2 and in subsequent Tabs. VIII and IX we compare the impact of the iron surface on the $\bigcirc \mathrm{MI} \square$ molecules. Please note that the changes of the Fermi energy of the surface correspond to the fraction of charge accepted on the molecule in our periodic model (with a large but ultimately constant number of electrons). At first, the simple (nonfunctionalized) imidazolium molecule is not an acceptor but a donor of electrons to the $\mathrm{Fe}(110)$ surface; see the charge transfer for $\bigcirc \mathrm{MIM}$ in Table VII. However, for the imidazolium molecule functionalized with either $\mathrm{Br}$,
$\mathrm{Cl}$, or $\mathrm{HSO}_{4}$ group, the charge transfer is towards these molecules, see $\bigcirc$ MIC , $\bigcirc \mathrm{MIB}$, and $\bigcirc$ MIS inTab.VII.

A crucial remark is to be made here. Equation (11) does not represent the actual charge transfer but rather the aptitude of a molecule to accept some additional charge. This means that the results in Table VII need to be supplemented with the analysis of the molecular charge, i.e. with the Bader charge analysis of the resultant spacial charge distribution. Moreover, the chemical properties of $\bigcirc$ MIM molecules in proximity of $\mathrm{Fe}(110)$ surface are a clear indicator of a charge transfer from molecule to the surface (i.e., its ionization). Note that the drastic changes of both hardness $\left(\eta_{\text {free }} \approx 1 \rightarrow \eta_{\text {surf }} \approx 2\right)$ and electronegativity $\left(\eta_{\text {free }} \approx 1 \rightarrow \eta_{\text {surf }} \approx 6\right)$ combined with lowering the HOMO-LUMO energies are what one expects is such a case.

As presented in Table VII, the compounds are divided into three distinctive groups: (i) 'pure' 

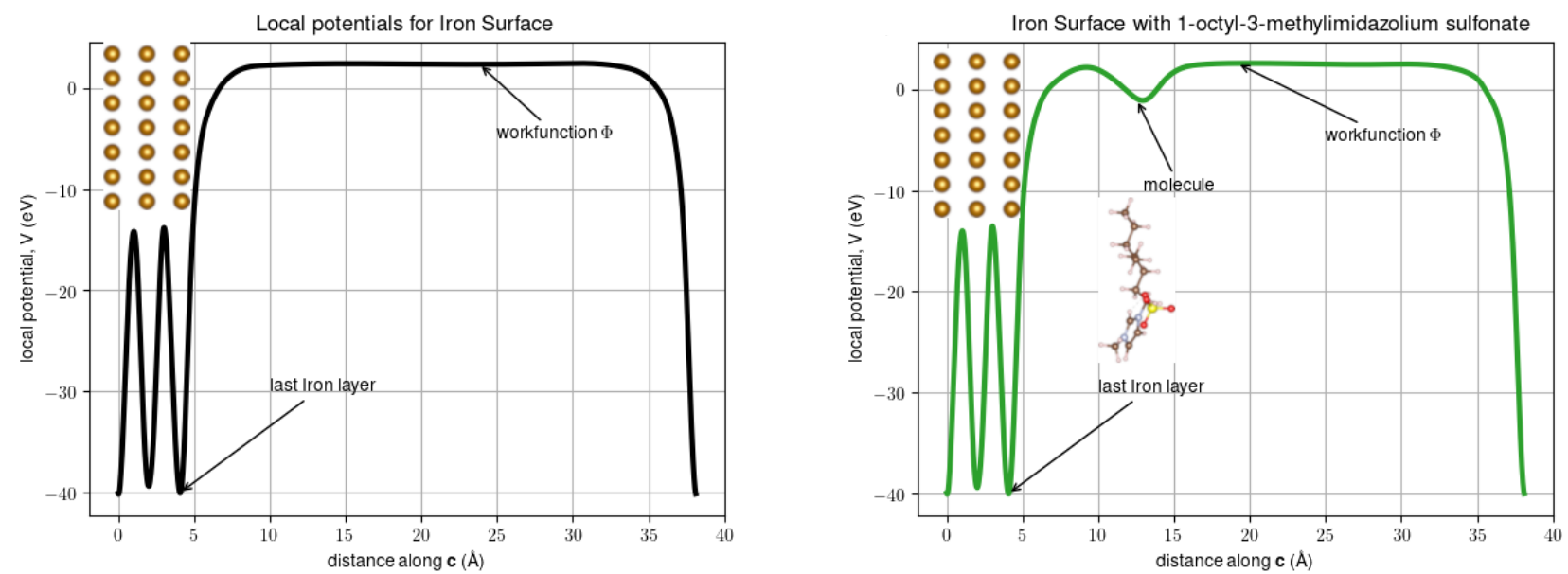

FIG. 9. The local potential (averaged along a and $\mathbf{b}$ directions) of pure Fe(110) surface (left) and the surface with OMIS molecule at an exemplary distance (right) versus the direction c. We define the proximity of the molecule to the surface as the difference between the last minimum corresponding to the iron layer and the minimum corresponding to the molecule.

TABLE VII. Fermi energy $E_{f}$ and the chemical properties at the electrons on the molecule at the optimal distance from iron surface, namely, the HOMO/LUMO energies, hardness $\eta$, electronegativity $\chi$, and charge transfer $\Delta N$ (via (11)) for molecule on-surface and an excpected charge transfer $\Delta N_{\text {free }}$ extrapolated from the properties of the free molecules (cf. Tab. V) - the Fermi energy $E_{f}=-2.4750 \mathrm{eV}$ - was taken as its value for the $\mathrm{Fe}(110)$ surface.

\begin{tabular}{c|ccccc|cc|c} 
& $E_{f}(\mathrm{eV})$ & $E_{\text {Hомо }}(\mathrm{eV}) E_{\text {LUMO }}(\mathrm{eV}) \eta(\mathrm{eV})$ & $\chi(\mathrm{eV})$ & $\Delta N(-\mathrm{e})$ & $\Delta N_{\text {free }}(-\mathrm{e})$ & $\Delta N_{\text {Bader }}$ \\
& & & & & & & \\
\hline \hline BMIM & -2.20 & -8.40 & -4.30 & 2.05 & 6.35 & $\mathbf{- 0 . 7 6}$ & $\mathbf{- 0 . 6 8}$ & -0.76 \\
HMIM & -2.18 & -8.58 & -4.46 & 2.06 & 6.52 & $\mathbf{- 0 . 8 4}$ & $\mathbf{- 0 . 7 0}$ & -0.68 \\
OMIM & -2.18 & -8.11 & -4.29 & 1.91 & 6.20 & $\mathbf{- 0 . 7 4}$ & $\mathbf{- 0 . 7 0}$ & -0.66 \\
\hline \hline BMIB & -2.41 & -5.55 & -1.86 & 1.84 & 3.71 & 0.64 & 0.21 & $\mathbf{0 . 3 6}$ \\
HMIB & -2.32 & -6.48 & -1.75 & 2.36 & 4.12 & 0.31 & 0.22 & $\mathbf{0 . 5 3}$ \\
OMIB & -2.29 & -6.46 & -1.76 & 2.35 & 4.11 & 0.32 & 0.22 & $\mathbf{0 . 8 1}$ \\
\hline BMIC & -2.41 & -5.70 & -1.77 & 1.97 & 3.73 & 0.59 & 0.20 & $\mathbf{0 . 5 8}$ \\
HMIC & -2.40 & -5.74 & -1.77 & 1.98 & 3.75 & 0.57 & 0.22 & $\mathbf{0 . 6 2}$ \\
OMIC & -2.30 & -6.66 & -1.74 & 2.46 & 4.20 & 0.27 & 0.22 & $\mathbf{1 . 0 8}$ \\
\hline BMIS & -2.43 & -5.87 & -1.85 & 2.01 & 3.86 & $\mathbf{0 . 5 2}$ & 0.31 & 0.16 \\
HMIS & -2.46 & -5.60 & -1.81 & 1.89 & 3.70 & $\mathbf{0 . 6 8}$ & 0.32 & 0.13 \\
OMIS & -2.49 & -5.46 & -1.72 & 1.87 & 3.59 & $\mathbf{0 . 7 9}$ & 0.32 & 0.11
\end{tabular}

TABLE VIII. Comparison of the energy scales: Fermi energy $E_{f}$, on-surface HOMO energy, free-molecule HOMO energy, on-surface LUMO energy, and free-molecule LUMO energy. All values in $\mathrm{eV}$.

\begin{tabular}{c|cc||cc} 
& $E_{\text {HOMO }}$ on Fe(110) & $E_{\text {Homo free }}$ & $E_{\text {Lumo on }} \mathrm{Fe}(110)$ & $E_{\text {LUMO }}$ free \\
\hline \hline BMIB & -5.55 & -4.47 & -1.86 & -1.67 \\
HMIB & -6.48 & -4.52 & -1.75 & -1.67 \\
OMIB & -6.46 & -4.56 & -1.76 & -1.67 \\
\hline BMIC & -5.70 & -4.70 & -1.77 & -1.49 \\
HMIC & -5.74 & -4.83 & -1.77 & -1.56 \\
OMIC & -6.66 & -4.81 & -1.74 & -1.55 \\
\hline BMIS & -5.87 & -5.32 & -1.85 & -1.82 \\
HMIS & -5.60 & -5.37 & -1.81 & -1.86 \\
OMIS & -5.46 & -5.39 & -1.72 & -1.82
\end{tabular}

$\bigcirc$ MIM molecules, (ii) Halogen enriched $\bigcirc \mathrm{MIB}$ and $\bigcirc \mathrm{MIC}$, and (iii) containing the hydrogen sulphate (see Fig. 10p. In (i) the molecules neither accept the electron from the surface (in fact they are donors as $\Delta N_{\text {Bader }}<0$ ) nor have the capacity to accept charge. Halogen-enriched (ii) molecules do not indicate smaller possibility of accepting a new electron as the alkyl chain becomes longer as an extra participation is already included in its electronic structure $\left(\Delta N_{\text {Bader }} \gg 0\right)$. Finally, in (iii) we do not observe significant charge being accepted on the $\bigcirc$ MIS molecules as $\Delta N_{\text {Bader }}$ decreases with the alkyl chain-length. The subgroups (ii) and (iii) are distinctively marked in the Inset of Fig. 10. Nevertheless, the result is compensated by growing (and significantly larger than other compounds) capacity for becoming an acceptor $(\Delta N \gg 0)$. These discrepancies are caused (most probably) by the finite size of the iron surface (chemical potential $\mu$ being low but still $>0$ ), causing the Feoriginated charge also to be limited. Technically, the finite-size scaling for the slab volume is to answer this 
TABLE IX. Comparison of on-surface and free-molecule hardness' $\eta$, electronegativities $\chi$, and charge transfers $\Delta N($ via $(11)$ ).

\begin{tabular}{c|cc||cc||rc} 
& $\eta(\mathrm{eV})$ on $\mathrm{Fe}(110) \eta(\mathrm{eV})$ free & $\chi(\mathrm{eV})$ on $\mathrm{Fe}(110) \chi(\mathrm{eV})$ free & $\Delta N$ on $\mathrm{Fe}(110) \Delta N$ free \\
\hline \hline BMIB & 1.84 & 1.40 & 3.71 & 3.07 & 0.64 & 0.21 \\
HMIB & 2.36 & 1.42 & 4.12 & 3.10 & 0.31 & 0.22 \\
OMIB & 2.35 & 1.44 & 4.11 & 3.11 & 0.32 & 0.22 \\
\hline BMIC & 1.97 & 1.60 & 3.73 & 3.09 & 0.59 & 0.20 \\
HMIC & 1.98 & 1.63 & 3.75 & 3.19 & 0.57 & 0.22 \\
OMIC & 2.46 & 1.64 & 4.20 & 3.19 & 0.27 & 0.22 \\
\hline BMIS & 2.01 & 1.75 & 3.86 & 3.57 & 0.52 & 0.31 \\
HMIS & 1.89 & 1.76 & 3.70 & 3.61 & 0.68 & 0.32 \\
OMIS & 1.87 & 1.79 & 3.59 & 3.62 & 0.79 & 0.32
\end{tabular}

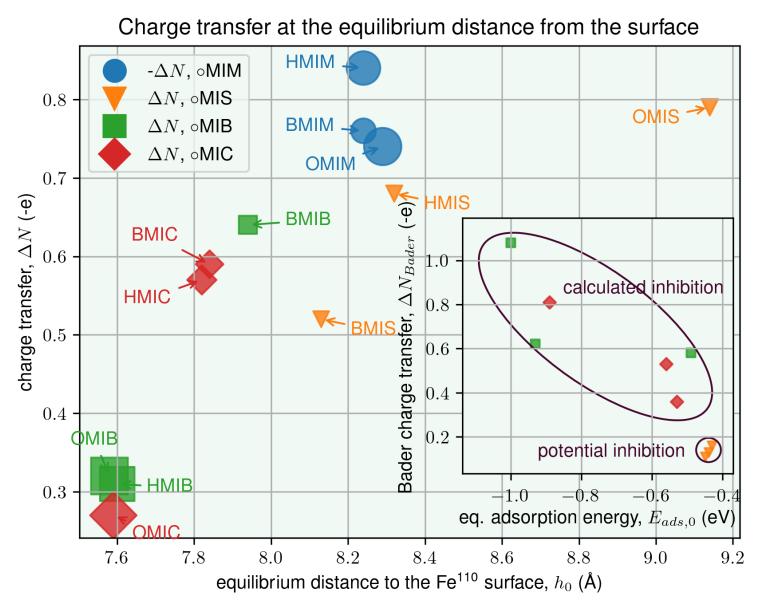

FIG. 10. Charge transfer $\Delta N$ at the equilibrium position (i.e. minimizing the adsorption energy $E_{\text {ads }}$ ) versus the equilibrium distance $h$ and (inset) the adsorption energy value at equilibrium. The size of the points corresponds to the minimal values of $E_{\text {ads }}$. Note the clear correlation between the equilibrium distance and the charge transfer for $\bigcirc \mathrm{MIB}$, $\bigcirc$ MIC, and $\bigcirc$ MIS , with no dependence for $\bigcirc$ MIM (donor) molecules.

question - a task feasible using the next generation HPC clusters with increased memory size and decreased node communication latency, as our calculations here reached the limits of the state-of-the-art supercomputers. ${ }^{[58}$ However, our results show important trends in inhibitor behaviour for the discussed compounds (cf. conclusions in Sec. VP.

\section{CONCLUSIONS}

In this paper we present a complementary picture of experimental and theoretical results showing the dependence of the efficiency of corrosion inhibition on the length of the alkyl chain of 1-alkyl-methylimidazolium chlorides, and 1-alkyl-methylimidazolium hydrogen sulphates. We not only show the qualitative differences between these two groups but also provide a comprehensive computational tool for labeling future candidate compounds as an extension to the already available approaches.

The inhibition efficiency of the imidazolium salts with various anions and various alkyl chain lengths was investigated through potentiodynamic polarization curves like corrosion current densities, EIS, weight loss measurements, and surface analysis. 1-octyl-3methylimidazolium hydrogen sulphate and 1-octyl-3methylimidazolium chloride proved to be mixed-type inhibitors with the predominant anodic inhibitive effect for mild steel. The inhibition efficiency of both ionic liquids is about $90 \%$ for the concentration of $0.001 \mathrm{M}$ and higher in $1 \mathrm{M} \mathrm{HCl}$ solutions. The results were compared with those obtained for 1-octyl-3methylimidazolium bromide ${ }^{32}$. The differences between 1-octyl-3-methylimidazolium salts were not significant. On the other hand, the inhibition efficiency of 1-butyl-3methylimidazolium hydrogen sulphate was much lower. It can be suggested that the alkyl chain length influences the inhibitor behaviour more than the type of anion for the same type of ionic liquid. The inhibition efficiency values obtained from the weight loss measurements were slightly higher than those from the electrochemical measurement. The reason probably consists of the slow formation of the protective film.

The quantum chemical calculations support the experimental findings when accounted for both the accepted and potentially accepted charge. While the total charge transfer $\left(\Delta N_{\text {tot }} \equiv \Delta N+\Delta N_{\text {Bader }}\right.$ oscillates around 1 for $\bigcirc \mathrm{MIC}$ and $\bigcirc \mathrm{MIB}$ (increasing $\sim 10 \%$ with doubling of the alkyl chain, its value for the $\bigcirc$ MIS compounds jumps by $\sim 35 \%$ (BMIS $\rightarrow$ OMIS, see all in Table VII). These trends are clearly not unravelled when the molecule is being assessed separately from the surface $\left(\Delta N_{\text {free }} \approx\right.$ const for $\bigcirc$ MIB , $\bigcirc \mathrm{MIC}$, and $\bigcirc \mathrm{MIS}$ ), as it was shown in the previous works. ${ }^{[57}$ It is important to note that although this separate approach does not predict the qualitative behaviour of the inhibition efficiency vs the chain length, it does, however, predict whether the molecule will become acceptor or not. 


\section{ACKNOWLEDGEMENTS}

This work was supported by the Technology Agency of the Czech Republic, project No. FV10089, Synthesis of ionic liquids in microwave reactor, by the ERDF in the IT4Innovations national supercomputing centre - path to exascale project (CZ.02.1.01/0.0/0.0/16_013/0001791) within the OPRDE, and by the project e-INFRA CZ (ID:90140) by the Ministry of Education, Youth and Sports of the Czech Republic.

\section{REFERENCES}

${ }^{a}$ Corresponding author: dominik.legut@vsb.cz

${ }^{1} \mathrm{~J}$. Fang and J. Li, Journal of Molecular Structure: THEOCHEM 593, 179 (2002)

${ }^{2}$ L. C. Murulana, A. K. Singh, S. K. Shukla, M. M. Kabanda, and E. E. Ebenso, Industrial \& Engineering Chemistry Research 51, 13282 (2012) https://doi.org/10.1021/ie300977d

${ }^{3}$ Q. Zhang and Y. Hua, Materials Chemistry and Physics 119, 57 (2010).

${ }^{4}$ M. A. Salam, B. Abdullah, A. Ramli, and I. Mujtaba, Journal of Molecular Liquids 224, 393 (2016)

${ }^{5}$ M. Quraishi, M. Rafiquee, and S. Khan, Journal of Applied Electrochemistry 37, 1153 (2007)

${ }^{6}$ H. Ashassi-Sorkhabi, B. Shabani, B. Aligholipour, and D. Seifzadeh, Applied Surface Science 252, 4039 (2006)

${ }^{7}$ D. quan Zhang, L. xin Gao, and G. ding Zhou, Corrosion Science 46, 3031 (2004)

${ }^{8}$ G. Vastag, A. Shaban, M. Vraneš, A. Tot, S. Belić, and S. Gadžurić, Journal of Molecular Liquids 264, 526 (2018)

${ }^{9}$ Y. Qiang, S. Zhang, L. Guo, X. Zheng, B. Xiang, and S. Chen, Corrosion Science 119, 68 (2017)

${ }^{10}$ S. Li, Y. Wang, S. Chen, R. Yu, S. Lei, H. Ma, and D. X. Liu, Corrosion Science 41, 1769 (1999)

${ }^{11}$ C. Verma, E. E. Ebenso, and M. Quraishi, Journal of Molecular Liquids 248, 927 (2017)

${ }^{12}$ H. Otmacic Curkovic, E. Stupnisek-Lisac, and H. Takenouti, Corrosion Science 51, 2342 (2009)

${ }^{13}$ A. Fateh, M. Aliofkhazraei, and A. Rezvanian, Arabian Journal of Chemistry 13, 481 (2020)

${ }^{14}$ S. Godlewska, J. Jezierska, K. Baranowska, E. Augustin, and A. Dołęga, Polyhedron 65, 288 (2013)

${ }^{15}$ P. C. Okafor and Y. Zheng, Corrosion Science 51, 850 (2009)

${ }^{16}$ Y. Guo, B. Xu, Y. Liu, W. Yang, X. Yin, Y. Chen, J. Le, and Z. Chen, Journal of Industrial and Engineering Chemistry 56, 234 (2017)

${ }^{17}$ Q. Zhang and Y. Hua, Electrochimica Acta 54, 1881 (2009)

${ }^{18}$ M. V. Diamanti, U. V. Velardi, A. Brenna, A. Mele, M. Pedeferri, and M. Ormellese, Electrochimica Acta 192, 414 (2016)

${ }^{19}$ A. Pourghasemi Hanza, R. Naderi, E. Kowsari, and M. Sayebani, Corrosion Science 107, 96 (2016)

${ }^{20}$ A. Ghanbari, M. Attar, and M. Mahdavian, Materials Chemistry and Physics 124, 1205 (2010)

${ }^{21}$ A. L. Chong, M. Forsyth, and D. R. MacFarlane, Electrochimica Acta 159, 219 (2015)

${ }^{22}$ C. Verma, L. Olasunkanmi, E. E. Ebenso, and M. Quraishi, Journal of Molecular Liquids 251, 100 (2018)

${ }^{23}$ N. V. Likhanova, M. A. Domínguez-Aguilar, O. Olivares-Xometl, N. Nava-Entzana, E. Arce, and H. Dorantes, Corrosion Science 52, 2088 (2010)

${ }^{24}$ M. Deyab, M. Zaky, and M. Nessim, Journal of Molecular Liquids 229, 396 (2017)

${ }^{20}$ O. A. Al-Rashed and A. A. Nazeer, Journal of Molecular Liquids 288, 111015 (2019)
${ }^{26}$ Y. Qiang, L. Guo, H. Li, and X. Lan, Chemical Engineering Journal 406, 126863 (2021)

${ }^{27}$ Y. Qiang, S. Zhang, B. Tan, and S. Chen, Corrosion Science 133, 6 (2018)

${ }^{28}$ Y. Qiang, H. Li, and X. Lan, Journal of Materials Science \& Technology 52, $63(2020)$

${ }^{29}$ I. Obot and I. B. Onyeachu, Journal of Molecular Liquids 249, 83 (2018)

${ }^{30}$ A. Ei-Awady, B. Abd-Ei-Nabey, and S. Aziz, Journal of The Electrochemical Society 139, 2149 (1992).

${ }^{31} \mathrm{~S}$. Abd El Rehim, M. A. Ibrahim, and K. Khalid, Materials Chemistry and Physics 70, 268 (2001)

ऊ̌̌̆ Langová, P. Pánek, J. Fojtášková, and Š. Vicherková, Transactions of the Indian Institute of Metals 71, 1368 (2018).

${ }^{33}$ Š. Langová, K. Marková, P. Pánek, and P. Váňová, in Proc Symp 27th International Conference on Metallurgy and Materials (METAL) , 965 (2018)

${ }^{34}$ E. Kowsari, S. Arman, M. Shahini, H. Zandi, A. Ehsani, R. Naderi, A. PourghasemiHanza, and M. Mehdipour, Corrosion Science 112, 73 (2016)

${ }^{55}$ X. Zheng, S. Zhang, W. Li, M. Gong, and L. Yin, Corrosion Science 95, 168 (2015)

${ }^{36}$ Y. Sasikumar, A. Adekunle, L. Olasunkanmi, I. Bahadur, R. Baskar, M. Kabanda, I. Obot, and E. Ebenso, Journal of Molecular Liquids 211, 105 (2015)

${ }^{3}$ S. Yesudass, L. Olasunkanmi, I. Bahadur, M. M. Kabanda, I. Obot, and E. Ebenso, Journal of the Taiwan Institute of Chemical Engineers 64, 252 (2016)

${ }^{3}$ S. Zhang, W. Lei, M. Xia, and F. Wang, Journal of Molecular Structure: THEOCHEM 732, 173 (2005)

${ }^{39}$ C. Verma, L. O. Olasunkanmi, I. Bahadur, H. Lgaz, M. Quraishi, J. Haque, E.-S. M. Sherif, and E. E. Ebenso, Journal of Molecular Liquids 273, 1 (2019)

${ }^{40}$ G. Kresse and J. Hafner, Phys. Rev. B 47, 558 (1993).

${ }^{41}$ G. Kresse and J. Hafner, Phys. Rev. B 49, 14251 (1994).

${ }^{42}$ G. Kresse and J. Furthmüller, Phys. Rev. B 54, 11169 (1996).

${ }^{43}$ G. Kresse and J. Furthmüller, Comput. Mater. Sci. 6, 15 (1996).

${ }^{44}$ J. Sun, A. Ruzsinszky, and J. P. Perdew, Phys. Rev. Lett. 115 036402 (2015).

${ }^{45}$ J. Sun, R. C. Remsing, Y. Zhang, Z. Sun, A. Ruzsinszky, H. Peng, Z. Yang, A. Paul, U. Waghmare, X. Wu, M. L. Klein, and J. P. Perdew, Nature Chemistry 8, 831 (2016).

${ }^{46}$ K. Pearson, Philosophical Magazine 2, 559 (1901).

${ }^{47}$ M. H. Keshavarz, K. Esmaeilpour, A. N. Golikand, and Z. Shirazi, Zeitschrift für anorganische und allgemeine Chemie 642, 906 (2016) https://onlinelibrary.wiley.com/doi/pdf/10.1002/zaac.201600230 ${ }^{48}$ M. Mousavi, M. Mohammadalizadeh, and A. Khosravan, Corrosion Science - CORROS SCI 53, 3086 (2011)

${ }^{49}$ E. Ferreira, C. Giacomelli, F. Giacomelli, and A. Spinelli, Materials Chemistry and Physics 83, 129 (2004).

${ }^{50}$ Y. Yan, W. Li, L. Cai, and B. Hou, Electrochimica Acta 53, $5953(2008)$

${ }^{51}$ J. Israelachvili, Intermolecular and Surface Forces 3rd Edition (Academic Press, 2011).

${ }^{52}$ W. Tyson and W. Miller, Surface Science 62, 267 (1977).

${ }^{53}$ I. H. Sahputra, A. Chakrabarty, O. Restrepo, O. Bouhali, N. Mousseau, C. S. Becquart, and F. ElMellouhi, physica status solidi (b) 254, 1600408 (2017) https://onlinelibrary.wiley.com/doi/pdf/10.1002/pssb.201600408

${ }^{54}$ R. F. W. Bader, Atoms in Molecules - A Quantum Theory (Oxford University Press, 1990).

${ }^{55}$ B. Wei, D. Legut, S. Sun, H. Wang, Z. Shi, H. Zhang, and R. Zhang, Materials \& Design 202, 109555 (2021)

${ }^{56}$ T. Wang, P. Zhai, D. Legut, L. Wang, X. Liu, B. Li, C. Dong, Y. Fan, Y. Gong, and Q. Zhang, Advanced Energy Materials 9, 1804000 (2019). https://onlinelibrary.wiley.com/doi/pdf/10.1002/aenm.201804000

${ }^{57}$ P. Parul Dohare, D. Chauhan, A. Sorour, and M. Quraishi, Mater. Discov. 9, 30 (2017). 
58"Euroexa project funded by h2020-eu.1.2.2., no. 754337," (20172021).

${ }^{59}$ V. Wang, N. Xu, J. C. Liu, G. Tang, and W.-T. Geng, "VASPKIT: A User-friendly Interface Facilitating Highthroughput Computing and Analysis Using VASP Code," (2019), arXiv:1908.08269 [cond-mat.mtrl-sci] 


\section{Appendix A: Formulae and the naming convention}

In this paper we study the compounds derived from imidazole, i.e., $\mathrm{C}_{3} \mathrm{H}_{4} \mathrm{~N}_{2}$ with a skeletal formula as in Fig. 11 with a methyl $\left(\mathrm{CH}_{3}\right)$ group at the position 3 and an alkyl chain (see below) at the position 1 . The compounds studied both experimentally and theoretically, i.e., 1-octyl-3-methylimidazolium chloride, 1-octyl-3-methylimidazolium hydrogen sulphate, and 1-butyl-3-methylimidazolium hydrogen sulphate, have their full skeletal formulae displayed in Fig. 12 .

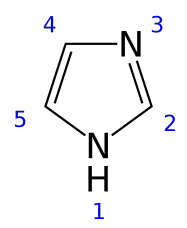

FIG. 11. A skeletal formula of an imidazolium molecule with a numbering convention of substituent groups used in this paper.

For simplicity, we refer to the molecules in question, i.e., 1- $\bigcirc$-3-methylimidazolium $\square$, as $\bigcirc$ MI $\square$, where we take the alkyl substituent group $\bigcirc$ as

\begin{tabular}{cc|c} 
alkyl & formula & symbol $(\bigcirc)$ \\
\hline butyl & $-C_{4} H_{9}$ & $\mathbf{B}$ \\
hexyl & $-C_{6} H_{13}$ & $\mathbf{H}$ \\
octyl & $-C_{8} H_{17}$ & $\mathbf{O}$
\end{tabular}

Furthermore, we take the functional group $\square$ as

\begin{tabular}{lc|c}
\multicolumn{1}{c|}{ group name } & formula & symbol $(\square)$ \\
\hline$\varnothing$ & & $\mathbf{M}$ \\
Bromide & $\mathrm{Br}$ & $\mathbf{B}$ \\
Chloride & $\mathrm{Cl}$ & $\mathbf{C}$ \\
Hydrogen sulphate & $-\mathrm{HSO}_{4}$ & $\mathbf{S}$
\end{tabular}

Hence, 1-octyl-3-methylimidazolium is being referred as OMIM, whereas 1-butyl-3-methylimidazolium bromide as BMIB.
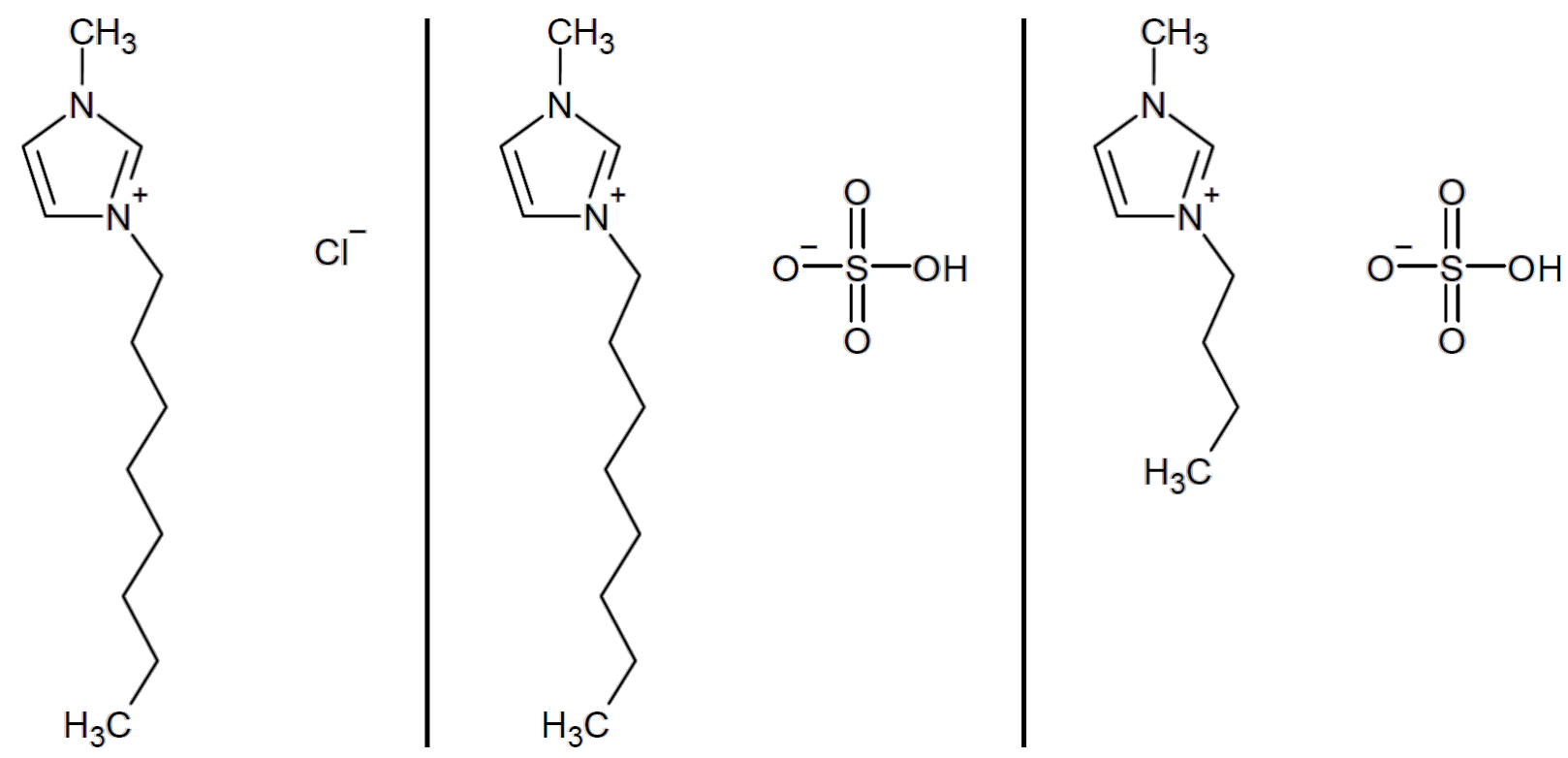

FIG. 12. Skeletal formulae of the experimentally studied molecules, i.e., the 1-octyl-3-methylimidazolium chloride (left), 1octyl-3-methylimidazolium hydrogen sulphate (center), and 1-butyl-3-methylimidazolium hydrogen sulphate (right). 


\section{Visualization of HOMO and LUMO}

The visualization of HOMO and LUMO is presented in Figs. 13 to 18 where we present the visualizations of the real-part of the HOMO and LUMO, using the VASPkit ${ }^{59}$.

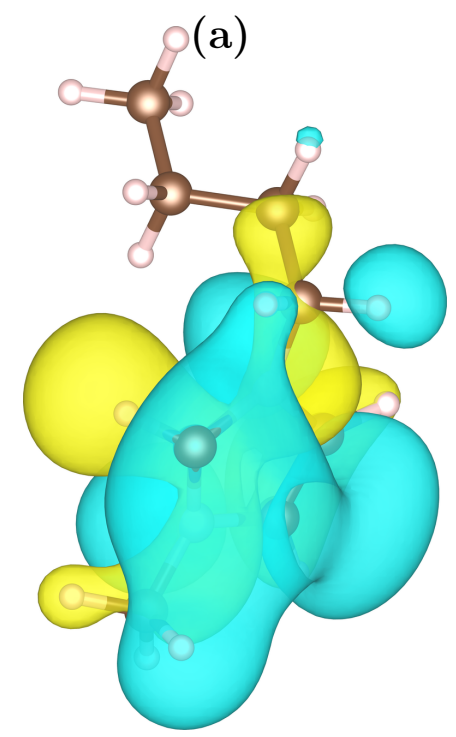

(b)

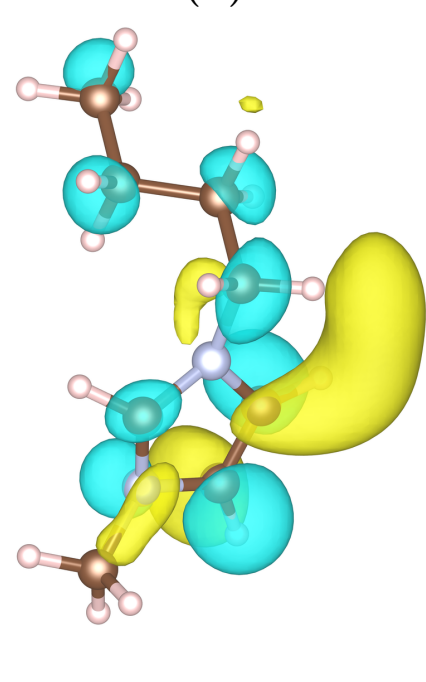

(c)

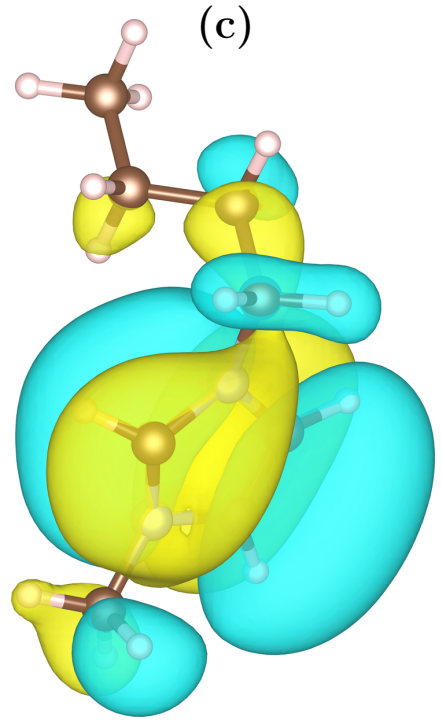

(d)

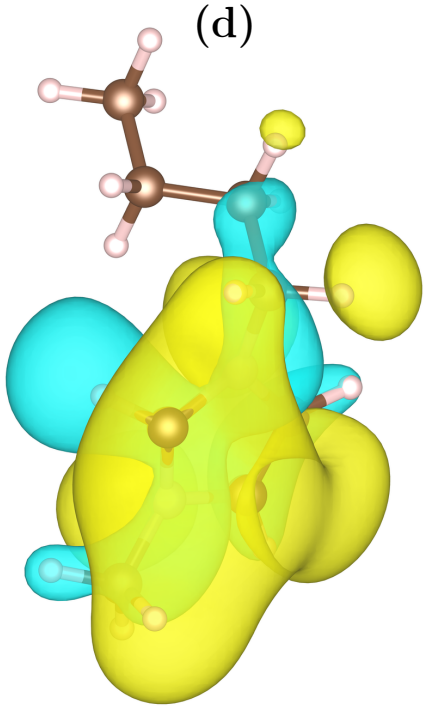

FIG. 13. 1-butyl-3-methylimidazolium: The highest occupied molecular orbital (HOMO) (a), (c) and the lowest unoccupied molecular orbital (LUMO) (b), (d) wavefunctions for spin $\uparrow$ and $\downarrow$ respectively.
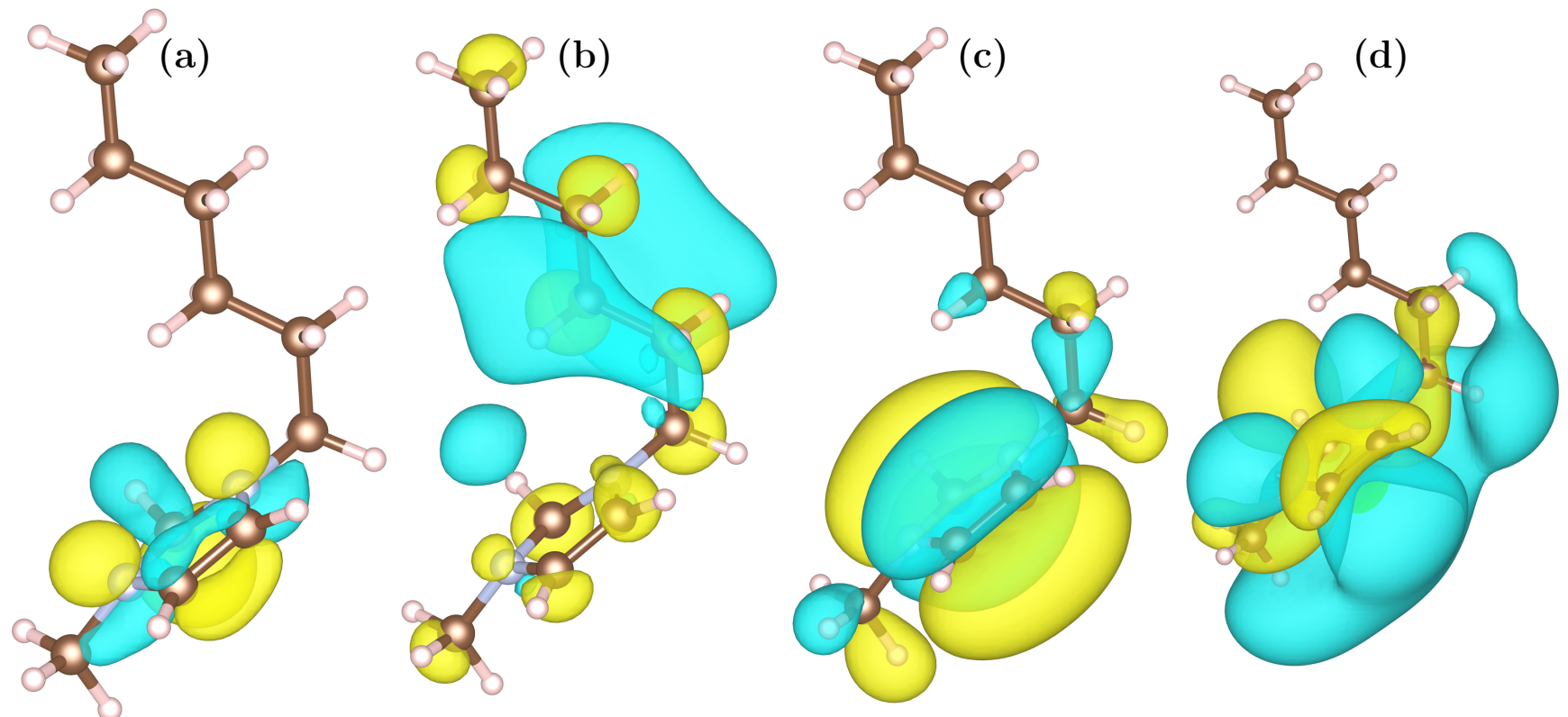

FIG. 14. 1-hexyl-3-methylimidazolium: The highest occupied molecular orbital (HOMO) (a), (c) and the lowest unoccupied molecular orbital (LUMO) (b), (d) wavefunctions for spin $\uparrow$ and $\downarrow$ respectively. 

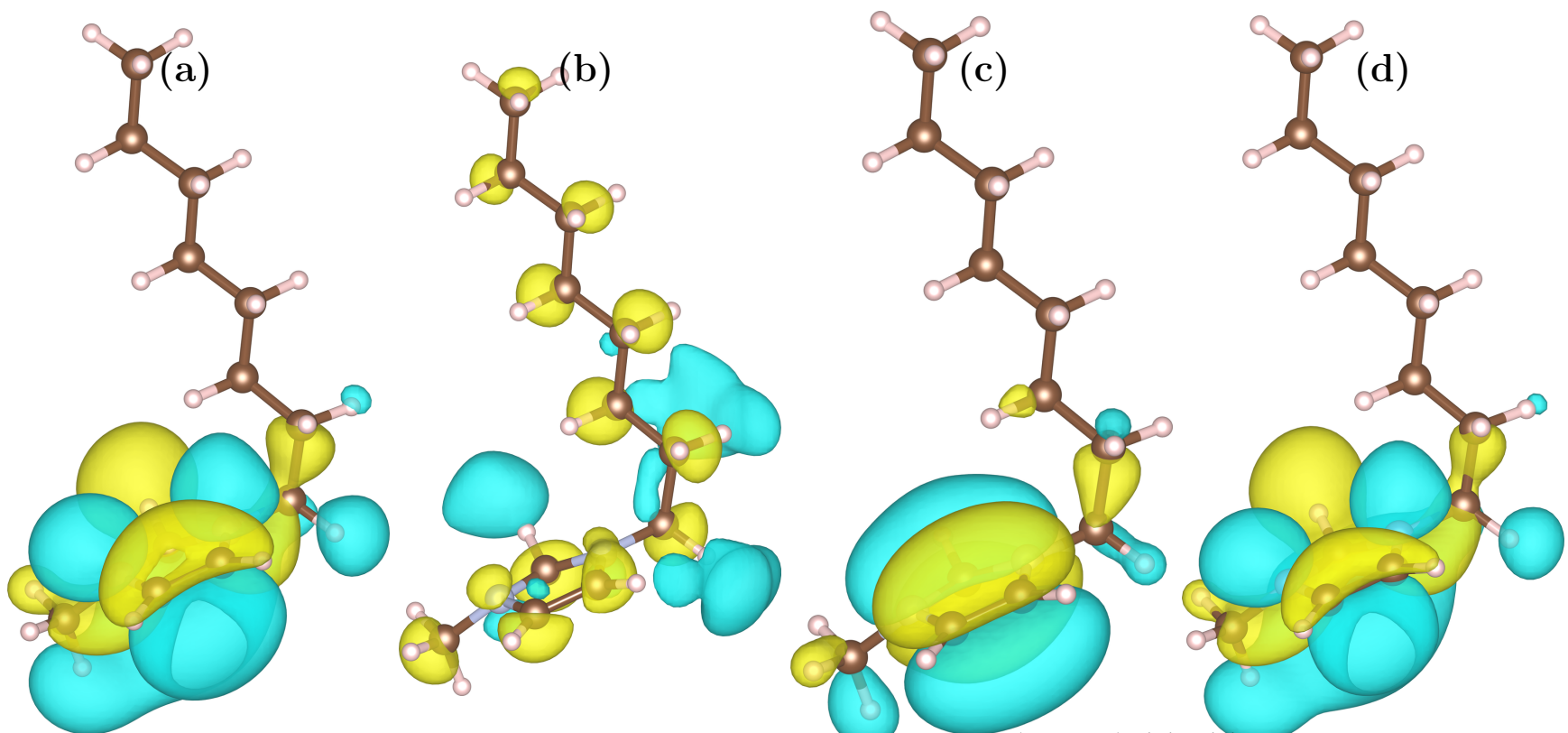

FIG. 15. 1-octyl-3-methylimidazolium: The highest occupied molecular orbital (HOMO) (a), (c) and the lowest unoccupied molecular orbital (LUMO) (b), (d) wavefunctions for spin $\uparrow$ and $\downarrow$ respectively. 
(a)

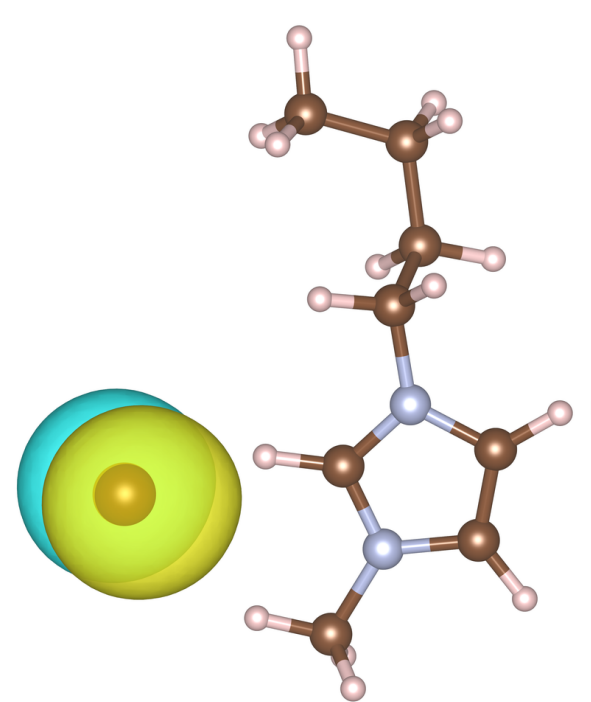

(b)

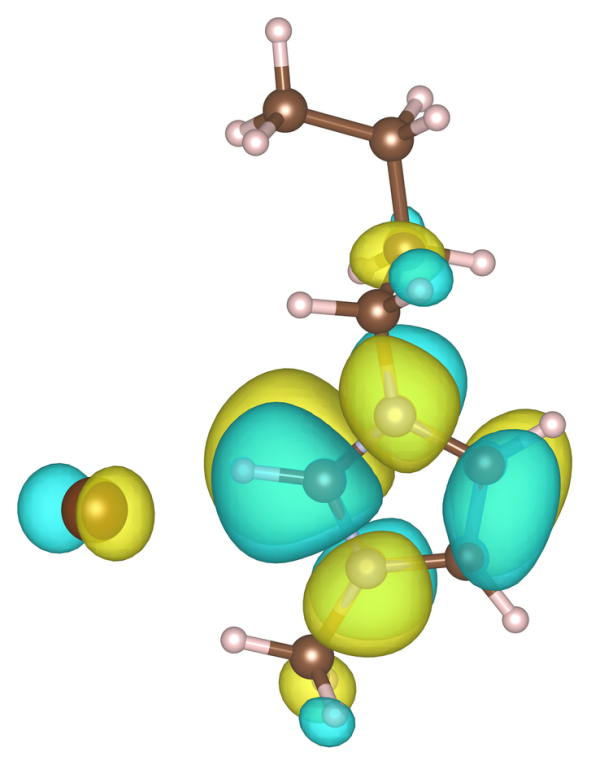

(c)

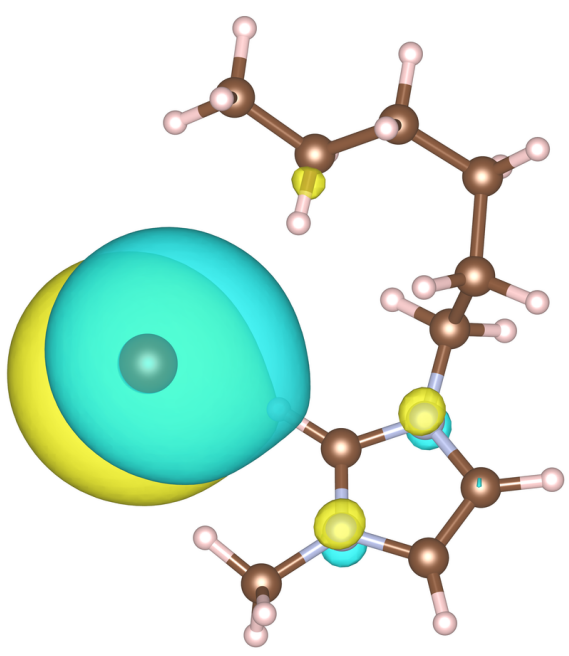

(d)

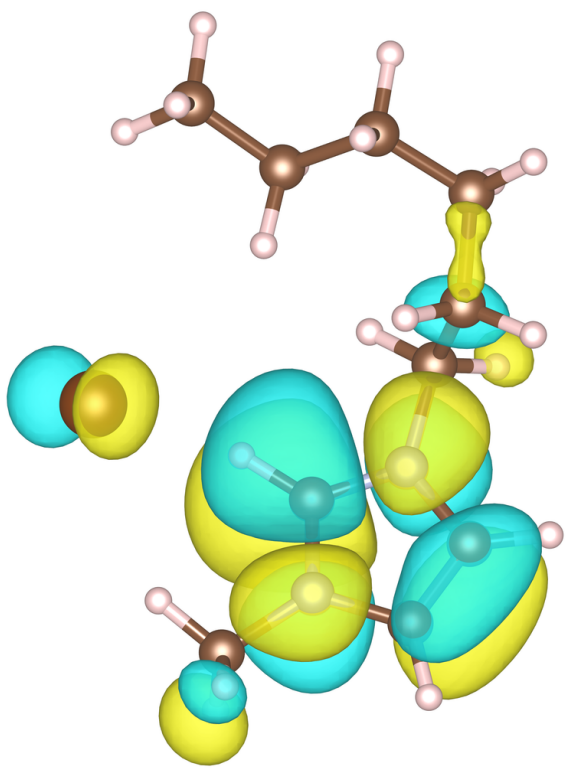

(e)

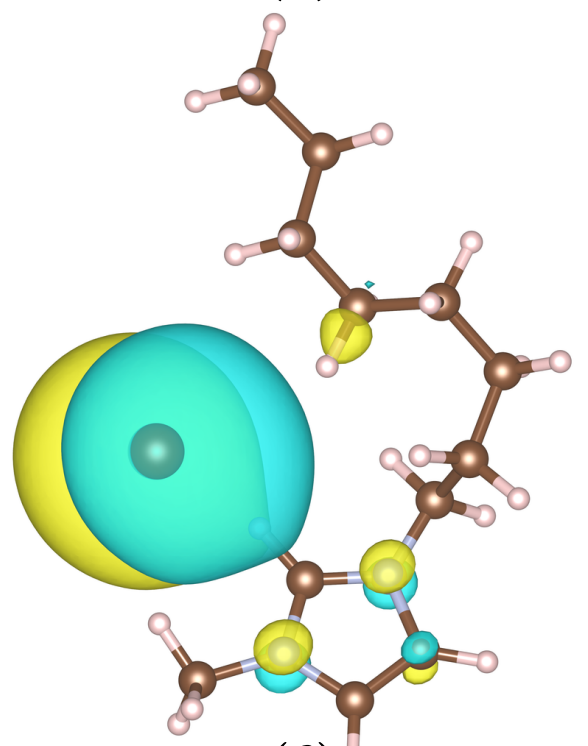

(f)

FIG. 16. The highest occupied molecular orbital (HOMO) (top) and the lowest unoccupied molecular orbital (LUMO) (bottom) wavefunctions of 1-butyl-3-methylimidazolium bromide (a), (b); 1-hexyl-3-methylimidazolium bromide (c), (d); 1-octyl-3-methylimidazolium bromide (e), (f). 
(a)

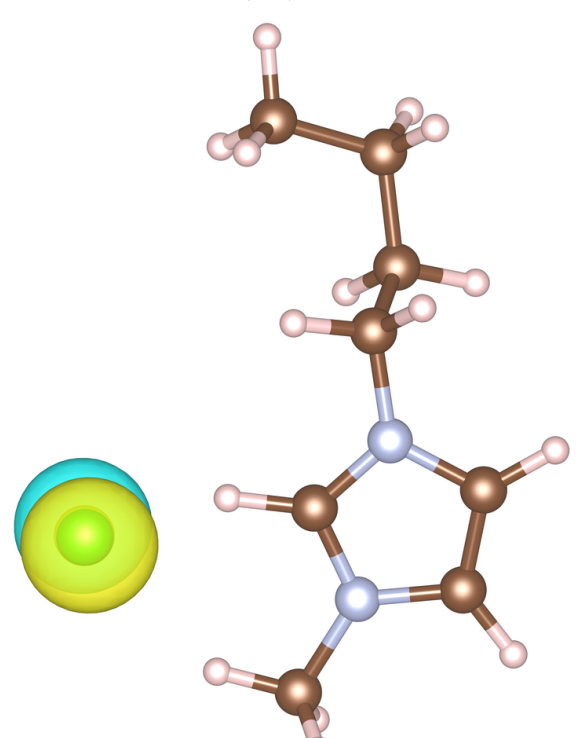

(b)

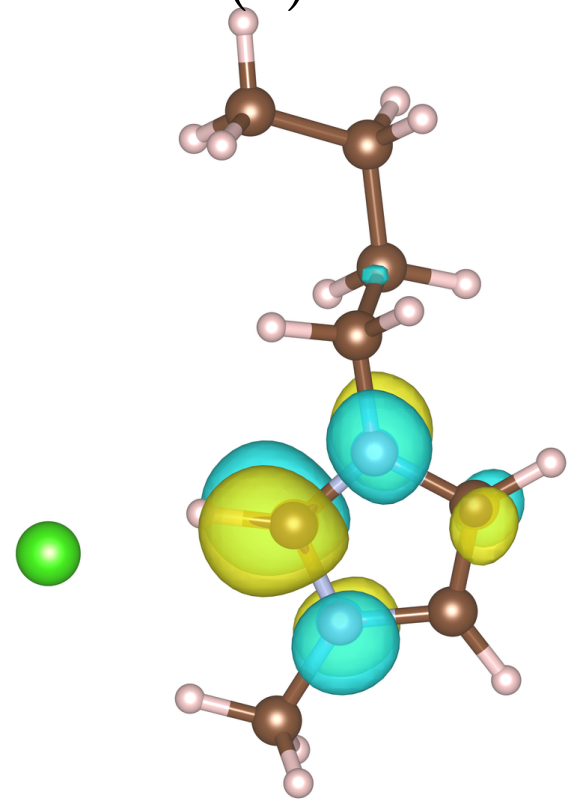

(c)

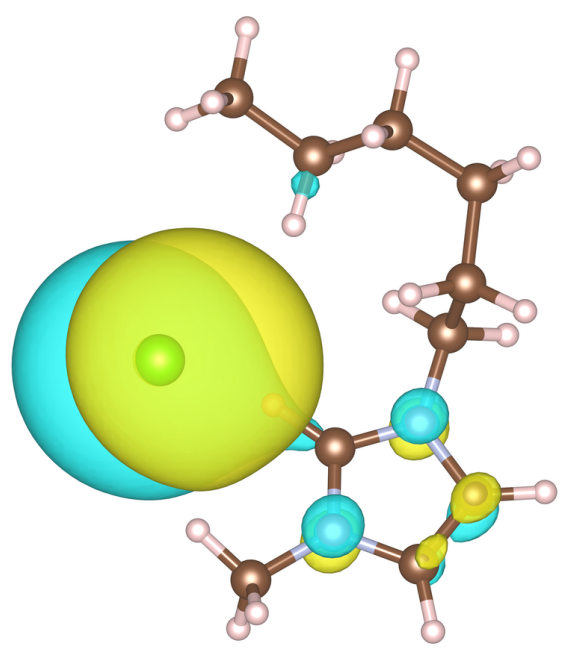

(d)

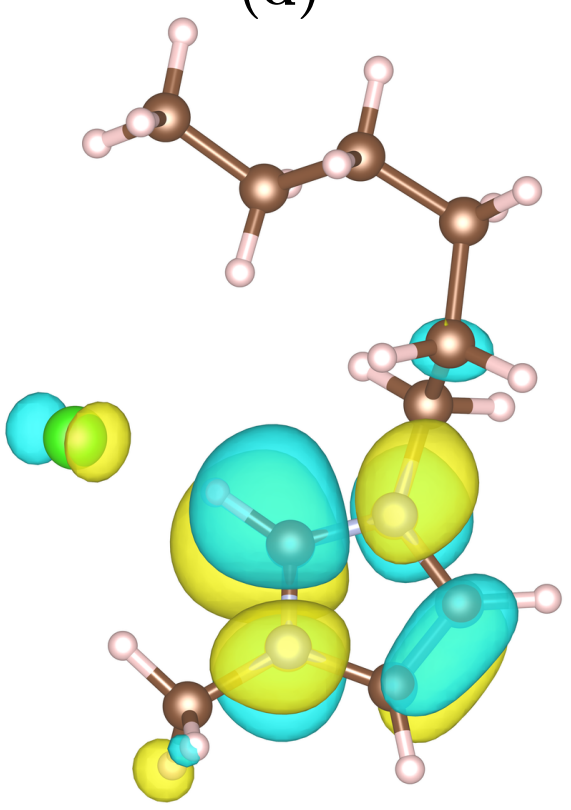

(e)

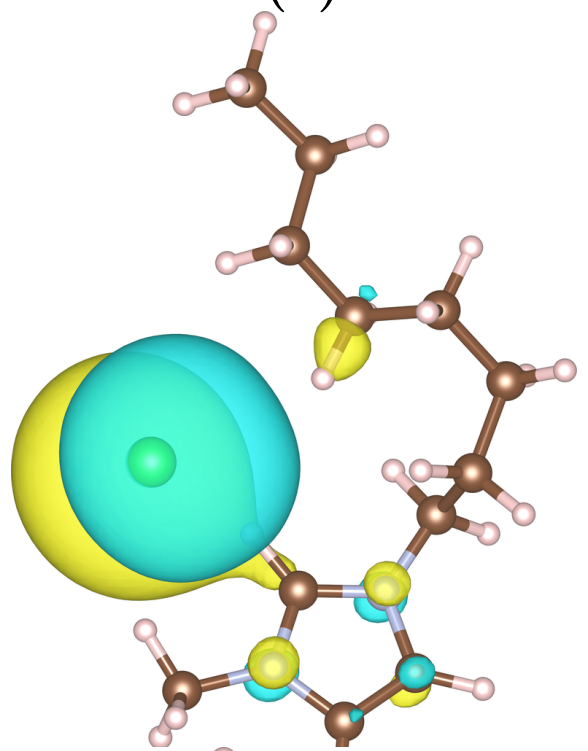

(f)

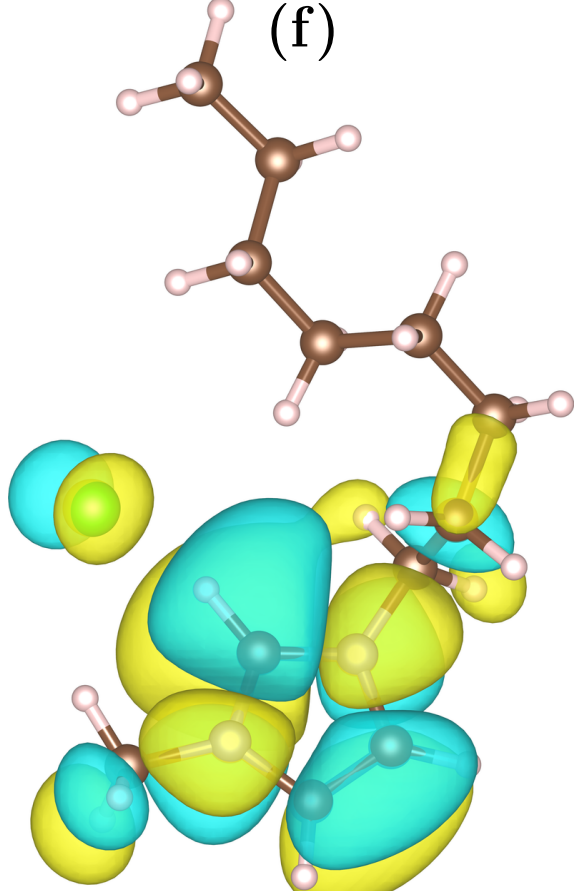

FIG. 17. The highest occupied molecular orbital (HOMO) (top) and the lowest unoccupied molecular orbital (LUMO) (bottom) wavefunctions of 1-butyl-3-methylimidazolium chloride (a), (b); 1-hexyl-3-methylimidazolium chloride (c), (d); 1-octyl-3-methylimidazolium chloride (e), (f). 
(a)

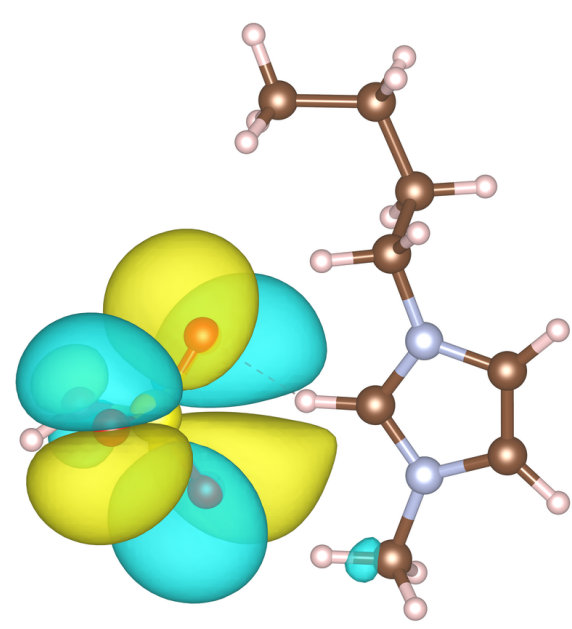

(b)

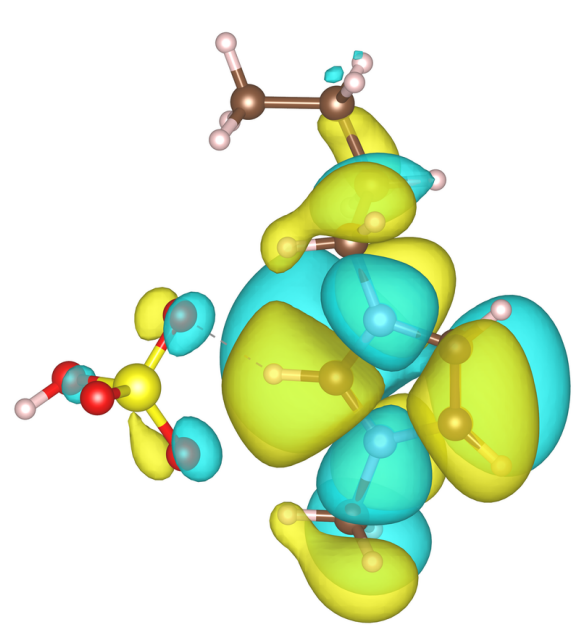

(c)

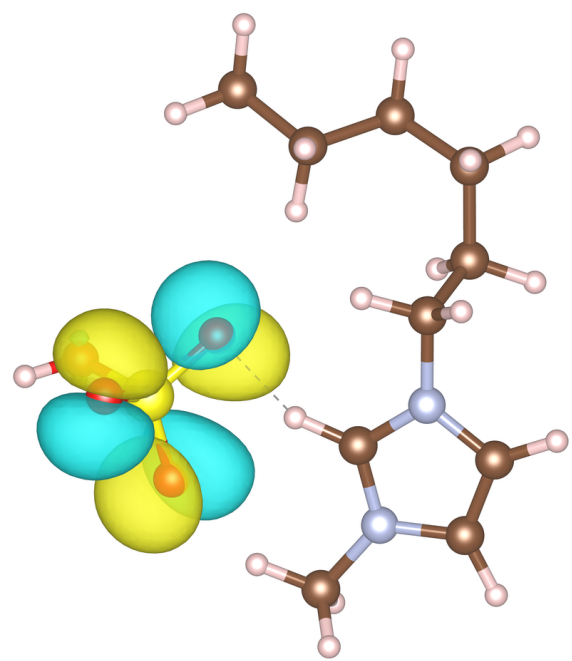

(d)

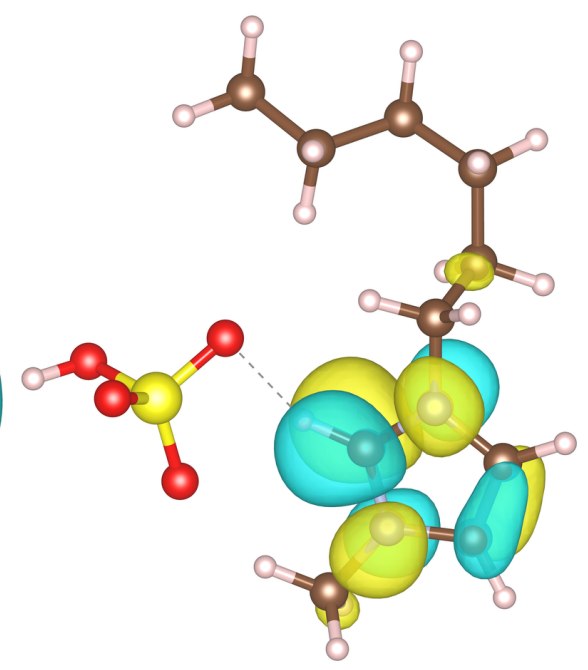

(e)

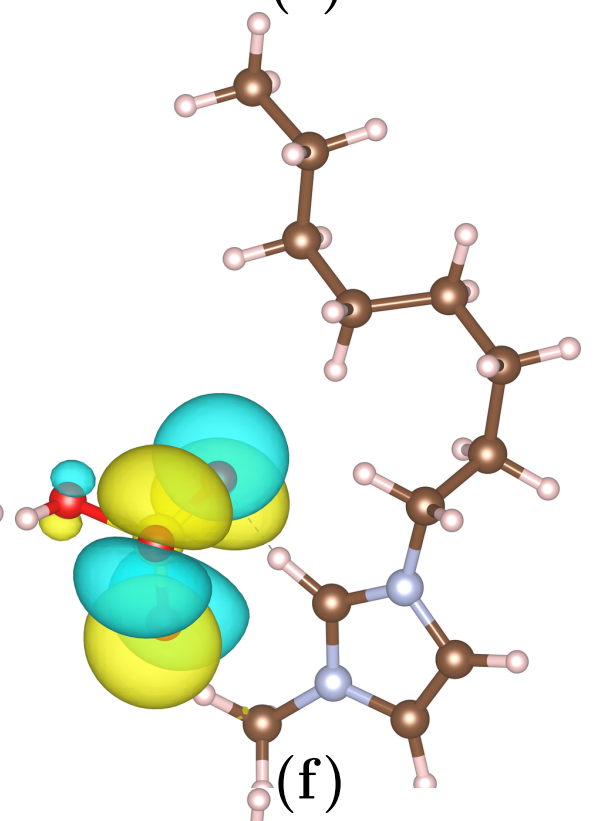

(f)

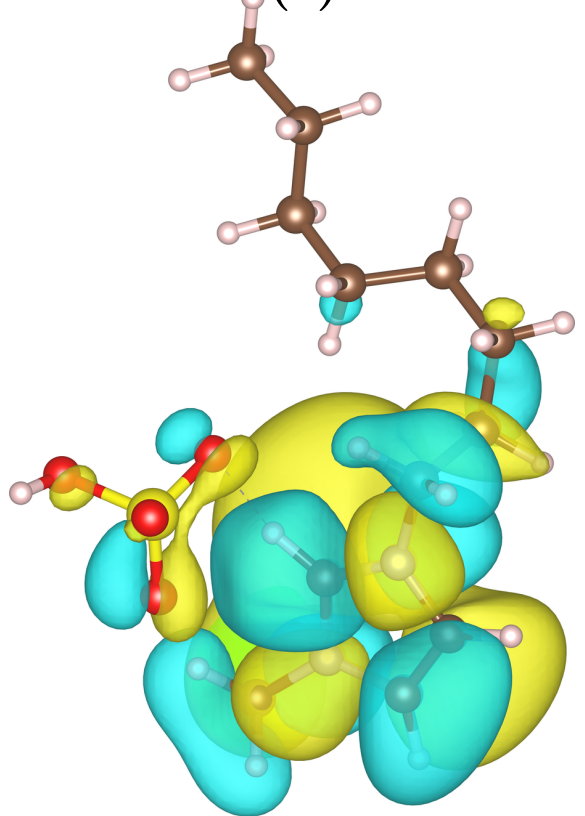

FIG. 18. The highest occupied molecular orbital (HOMO) (top) and the lowest unoccupied molecular orbital (LUMO) (bottom) wavefunctions of 1-butyl-3-methylimidazolium hydrogen sulphate (a), (b); 1-hexyl-3-methylimidazolium hydrogen sulphate (c), (d); 1-octyl-3-methylimidazolium hydrogen sulphate (e), (f). 